NASA/TP-1998-206554

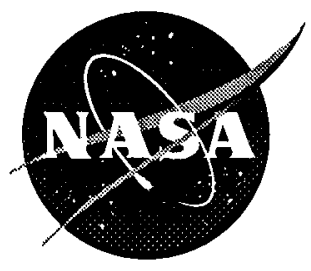

\title{
Propulsion Flight Research at NASA Dryden From 1967 to 1997
}

Frank W. Burcham, Jr., Ronald R. Ray, Timothy R. Conners, and Kevin R. Walsh Dryden Flight Research Center

Edwards, California

National Aeronautics and

Space Administration

Dryden Flight Research Center

Edwards, California 93523-0273 


\section{NOTICE}

Use of trade names or names of manufacturers in this document does not constitute an official endorsement of such products or manufacturers, either expressed or implied, by the National Aeronautics and Space Administration.

Available from the following:

NASA Center for AeroSpace Information (CASI)

7121 Standard Drive

Hanover, MD 21076-1320

(301) 621-0390
National Technical Information Service (NTIS) 5285 Port Royal Road Springfield, VA 22161-2171

(703) $487-4650$ 


\title{
PROPULSION FLIGHT RESEARCH AT NASA DRYDEN FROM 1967 TO 1997
}

\author{
Frank W. Burcham, Jr., ${ }^{*}$ Ronald J. Ray, ${ }^{\dagger}$ Timothy R. Conners, $\stackrel{+}{+}$ and Kevin R. Walsh ${ }^{\S}$ \\ NASA Dryden Flight Research Center \\ Edwards, California 93525
}

\begin{abstract}
From 1967 to 1997, pioneering propulsion flight research activities have been conceived and conducted at the NASA Dryden Flight Research Center. Many of these programs have been flown jointly with the United States Department of Defense, industry, or the Federal Aviation Administration. Propulsion research has been conducted on the XB-70, F-111A, F-111E, YF-12, JetStar, B-720, MD-11, F-15, F-104, Highly Maneuverable Aircraft Technology, F-14, F/A-18, SR-71, and the hypersonic X-15 airplanes. Research studies have included inlet dynamics and control, in-flight thrust computation, integrated propulsion controls, inlet and boattail drag, wind tunnel-to-flight comparisons, digital engine controls, advanced engine control optimization algorithms, acoustics, antimisting kerosene, in-flight lift and drag, throttle response criteria, and thrust-vectoring vanes. A computer-controlled thrust system has been developed to land the F-15 and MD-11 airplanes without using any of the normal flight controls. An F-15 airplane has flown tests of axisymmetric thrustvectoring nozzles. A linear aerospike rocket experiment has been developed and tested on the SR-71 airplane. This paper discusses some of the more unique flight programs, the results, lessons learned, and their impact on current technology.
\end{abstract}

\section{Nomenclature}

\section{ACTIVE Advanced Control Technology for} Integrated Vehicles

ADECS adaptive engine control system

AGL above ground level (radar altitude)

\footnotetext{
*Assistant Director, Research Engineering, Associate Fellow.

Acting Chief, Propulsion and Performance Branch.

Aerospace Engineer, AIAA member.

$\$$ Aerospace Engineer.

Copyright (C) 1998 by the American Institute of Aeronautics and Astronautics, Inc. No copyright is asserted in the United States under Title 17, U.S. Code. The U.S. Government has a royalty-free license to exercise all rights under the copyright claimed herein for Governmental purposes. All other rights are reserved by the copyright owner.
}

$\begin{array}{ll}\text { AMK } & \text { antimisting kerosene } \\ \text { APF } & \text { advanced prop fan } \\ \text { ARI } & \text { aileron-rudder interconnect } \\ \text { CID } & \text { controlled impact demonstration } \\ \text { CFD } & \text { computational fluid dynamics } \\ \text { DEEC } & \text { digital electronic engine control } \\ \text { EMD } & \text { engine model derivative } \\ \text { EPR } & \text { engine pressure ratio } \\ \text { ERD } & \text { Extended Range Demonstration } \\ \text { HARV } & \text { High Alpha Research Vehicle } \\ \text { HIDEC } & \text { Highly Integrated Digital Electronic } \\ & \text { Control } \\ \text { HiMAT } & \text { Highly Maneuverable Aircraft Technology } \\ \text { HISTEC } & \text { high stability engine control } \\ \text { HRE } & \text { hypersonic research engine } \\ \text { ILS } & \text { instrument landing system } \\ \text { IPE } & \text { increased performance engine } \\ \text { IPCS } & \text { integrated propulsion control system } \\ \text { LASRE } & \text { Linear Aerospike SR-71 Experiment } \\ \text { PCA } & \text { propulsion-controlled aircraft } \\ \text { PSC } & \text { performance-seeking control } \\ \text { PSL } & \text { Propulsion System Laboratory (NASA } \\ & \text { Lewis Research Center) } \\ \text { SST } & \text { supersonic transport } \\ \text { TACT } & \text { Transonic Aircraft Technology } \\ \text { USAF } & \text { United States Air Force } \\ & \quad \text { Introduction } \\ \end{array}$

Advancements in propulsion have been responsible for many of the huge strides made in aviation. Because of the continuing need to study, evaluate, and 
demonstrate new propulsion concepts and the unique opportunities offered by the actual flight environment, the NASA Dryden Flight Research Center (Edwards, California) has been conducting propulsion flight research for the past 50 years. Flight research has been shown to be a cost-effective way to assist, accelerate development of, and transition propulsion technology into production. ${ }^{1}$

Beginning in the 1960's, with the advent of afterburning turbofan engines and the mixed compression inlet, new phenomena needed to be investigated in flight. These phenomena included highfrequency pressure dynamics that were measured in the $\mathrm{XB}-70$ and the F-111A aircraft. ${ }^{2}$ Hypersonic propulsion system research was also studied on the X-15 airplane. ${ }^{3}$

Control integration became practical with the advent of digital control systems in the early 1970's. Digital flyby-wire flight controls were pioneered at NASA Dryden, and the first digital inlet/engine controls were flown in the F-111E integrated propulsion control system (IPCS) program in $1976 .{ }^{4} \mathrm{~A}$ follow-on activity was flown on the YF-12 airplane, ${ }^{5}$ and later the controls went into a fleet retrofit on the SR-71 airplane. The Highly Integrated Digital Electronic Control (HIDEC) program on the F-15 airplane developed a series of control integration technologies. $^{6}$

Prediction of propulsion system characteristics has long relied on wind-tunnel tests. Validating wind-tunnel test techniques is important and has been accomplished during several programs at NASA Dryden, including the YF- $12,{ }^{7}$ the F-15, ${ }^{8}$ and the F/A-18 High Alpha Research Vehicle (HARV) programs. ${ }^{9}$

In addition, drag validation requires a knowledge of in-flight thrust. Various techniques for determining inflight thrust have been studied at NASA Dryden for 50 years. ${ }^{10-12}$ Aircraft used to conduct thrust measurement research have included the $\mathrm{XB}-70$, the F-111 series, the F-15, the X-29, the Highly Maneuverable Aircraft Technology (HiMAT), and the F/A-18 aircraft.

Acoustic tests have also been done at NASA Dryden during the past 35 years. Aircraft involved have included the F/A-18, F-16XL, F-15, F-111, YF-12, and XB-70 airplanes; business jets; and the $\mathrm{C}-140$ JetStar airplane. Airframe noise tests have also been conducted, including tests with all engines off.

One of the more spectacular tests was the intentional crash test of a B-720 airplane carrying antimisting kerosene (AMK) fuel. Propulsion engineers at NASA Dryden developed, flight-qualified, and flight-tested the fuel degrader equipment on the engines. ${ }^{13}$

Emergency flight control using only engine thrust has been pioneered by NASA Dryden and flight-tested on the F-15 and MD-11 airplanes. ${ }^{14}$ Tests continued on the B-747 and C-17 airplanes.

In the current decade, work in hypersonics and space propulsion has increased. Major efforts include the linear aerospike rocket engine test on the SR-71 airplane and planning for the Hyper-X project.

This paper summarizes the propulsion research accomplishments from 1967 to 1997. Examples of important contributions are presented, with particular attention given to the unique contributions of flight research and lessons learned operating in the flight environment.

\section{History of NASA Dryden Propulsion Flight Research}

Figure 1 shows the major propulsion flight research activities conducted at NASA Dryden from 1967 to 1997. The research is shown in categories of performance, air inlet research, engine research, nozzle research, acoustics, propulsion control, hypersonic propulsion, and other. Many of these activities were conducted jointly with other NASA centers, the United States Department of Defense, and industry. Some of the more pertinent activities will be discussed in the following sections.

\section{The XB-70 In-Flight Thrust}

Determination of airplane drag is often an objective of flight test. The net thrust of the propulsion system is the major component in determining airplane drag. In 1967, flight tests to measure lift and drag were flown on the $\mathrm{XB}-70$ airplane. This testing was done to validate the methods to be used for the then-proposed supersonic transport (SST). The XB-70 airplane was a large, deltawing bomber capable of extended cruise at Mach 3.0. The propulsion system consisted of two-dimensional, mixed-compression, vertical ramp inlets feeding six YJ93 (General Electric, Evandale, Ohio) afterburning turbojet engines.

One of the objectives of the $\mathrm{XB}-70$ program was to determine the drag of a supersonic cruise airplane; the six engines and two inlets were extensively instrumented to measure propulsion system performance. The gas 


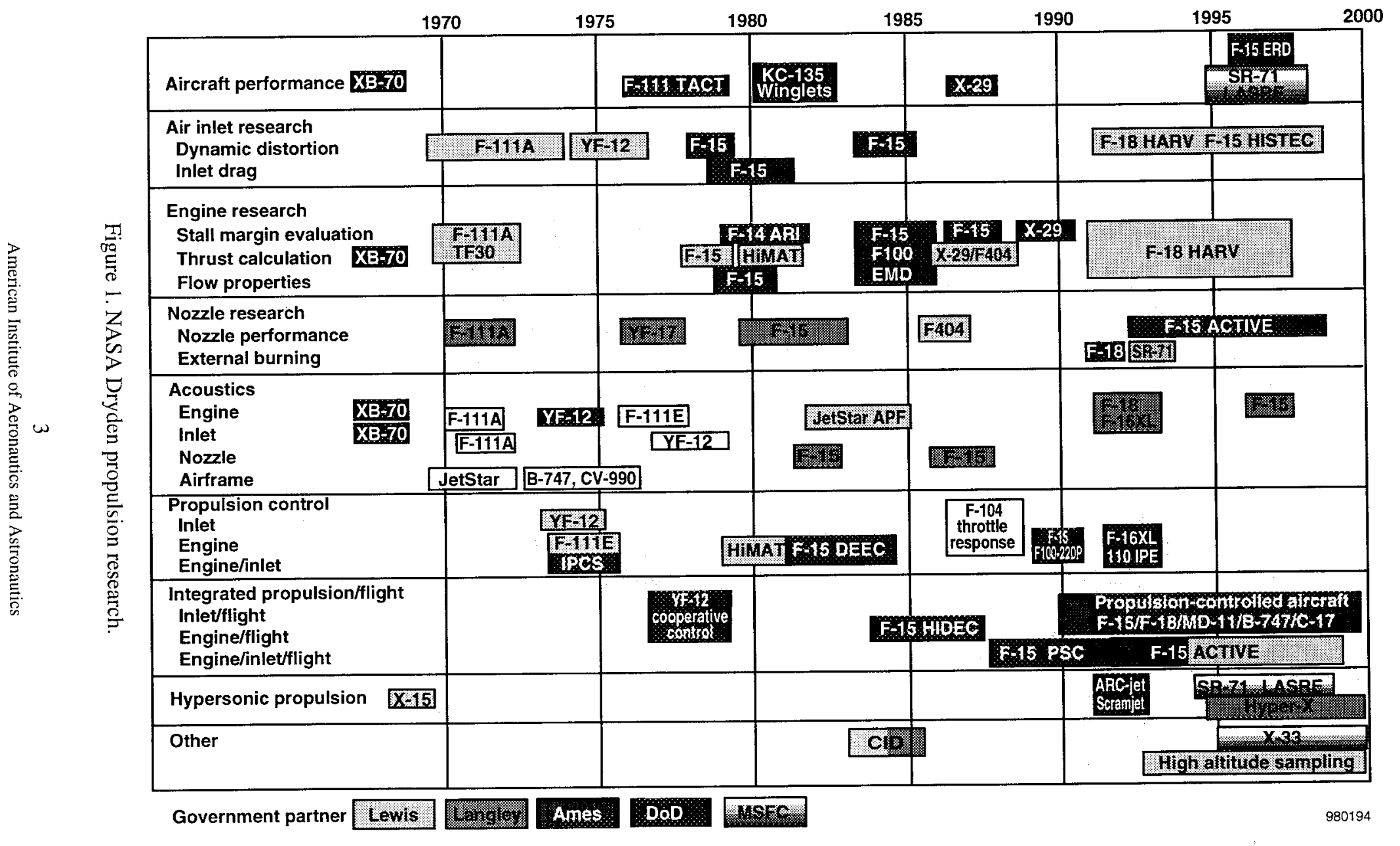


generator method of thrust calculation was used for the YJ93 engines. Sufficient redundancy in the measurements was available to use two variations, the pressure-area and the mass flow-temperature method. One thrust calculation method required precise nozzle pressure and nozzle area measurement, while the other method needed precise rotor speed and fuel flow measurement. Data were obtained from a ground static thrust test in which the $\mathrm{XB}-70$ thrust was measured by the thrust stand at Edwards Air Force Base (California). Data agreed within \pm 4 percent over the thrust range (fig. 2).

The inlet throat area was reduced to increase the throat Mach number for acoustic tests; the resulting higher distortion did not affect the thrust calculation more than 1-2 percent. The accurate in-flight thrust calculation made possible an extensive wind tunnel-to-flight drag analysis. ${ }^{15}$ Results showed that cruise lift-to-drag ratio was properly predicted, but that transonic predictions were in error. In particular, transonic pitching-moment predictions were in error, causing the XB-70 airplane to have larger-than-predicted elevon deflections, increasing transonic drag.

Base pressures around the engines were also lower than predicted, causing increased transonic drag. The resulting higher transonic drag decreased range by 24 percent. The propulsion system performance in general matched predictions, but the very long, heavy inlet ducts and large base area were not suitable for the proposed SST. Thrust calculation research continued to be a major activity at NASA Dryden the next 30 years.

\section{The Hypersonic Research Scramjet}

In 1967, NASA was involved in planning for flight tests of the hypersonic research engine (HRE), an axisymmetric variable geometry ramjet/scramjet engine fueled with hydrogen and designed to be flown on the $\mathrm{X}-15$ research airplane. A nonflowing ramjet shape the size of the HRE was fabricated and flown to determine the effects on the flow field and on overall X-15 stability, control, and performance. The nonflowing ramjet was flown to Mach 6.72. Pressure probes on the ramjet and pylon measured the local flow conditions, local Mach number, and flow angularity.

Figure 3 shows local angle of attack over the Mach range, and shows that for better flow alignment, the ramjet would have needed to be canted down approximately $2^{\circ}$. On a flight to Mach 6.7 , the shock waves from the ramjet spike impinged on the lower ventral fin and caused a local hot spot that burned through the ablative coating and the high-temperature nickel-cobalt alloy skin, causing the ramjet to separate from the X-15 airplane. ${ }^{3}$

The actual HRE did not fly because of delays in development, but was tested in a ground facility at the NASA Lewis Research Center (Cleveland, Ohio). In the
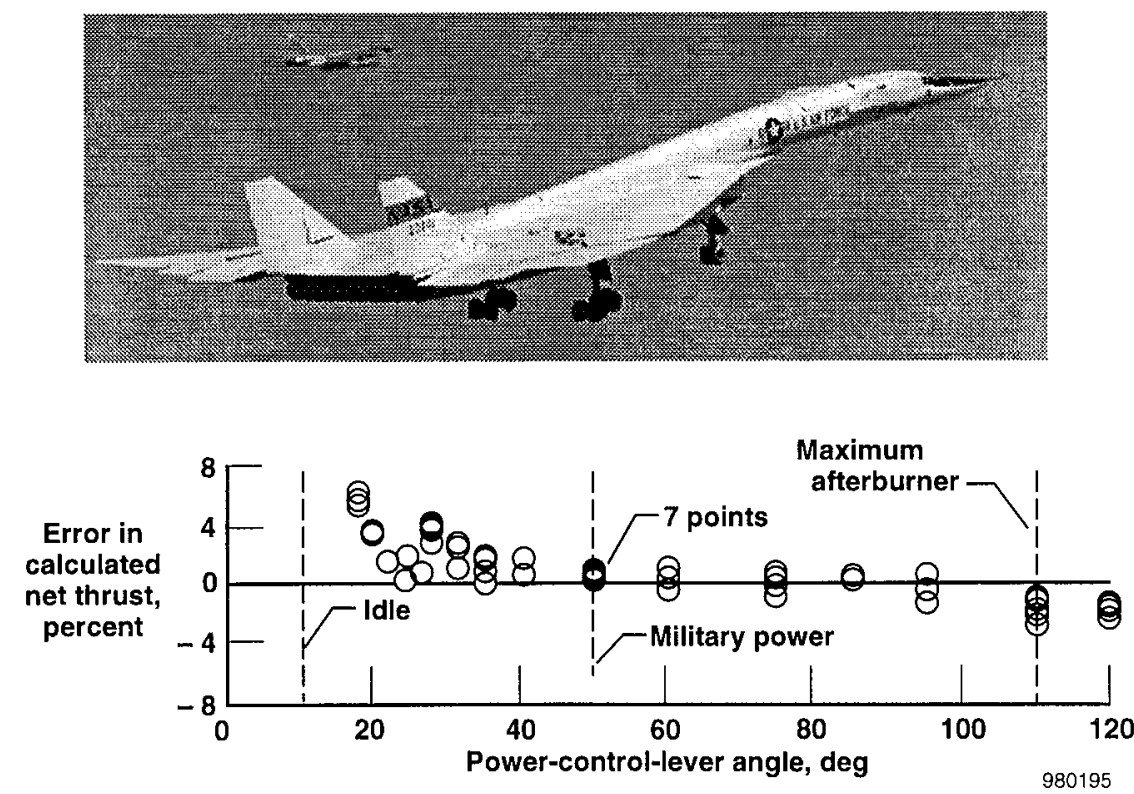

Figure 2. Thrust calculation accuracy, gas generator method, XB-70 airplane, ground static thrust stand. ${ }^{2}$ 


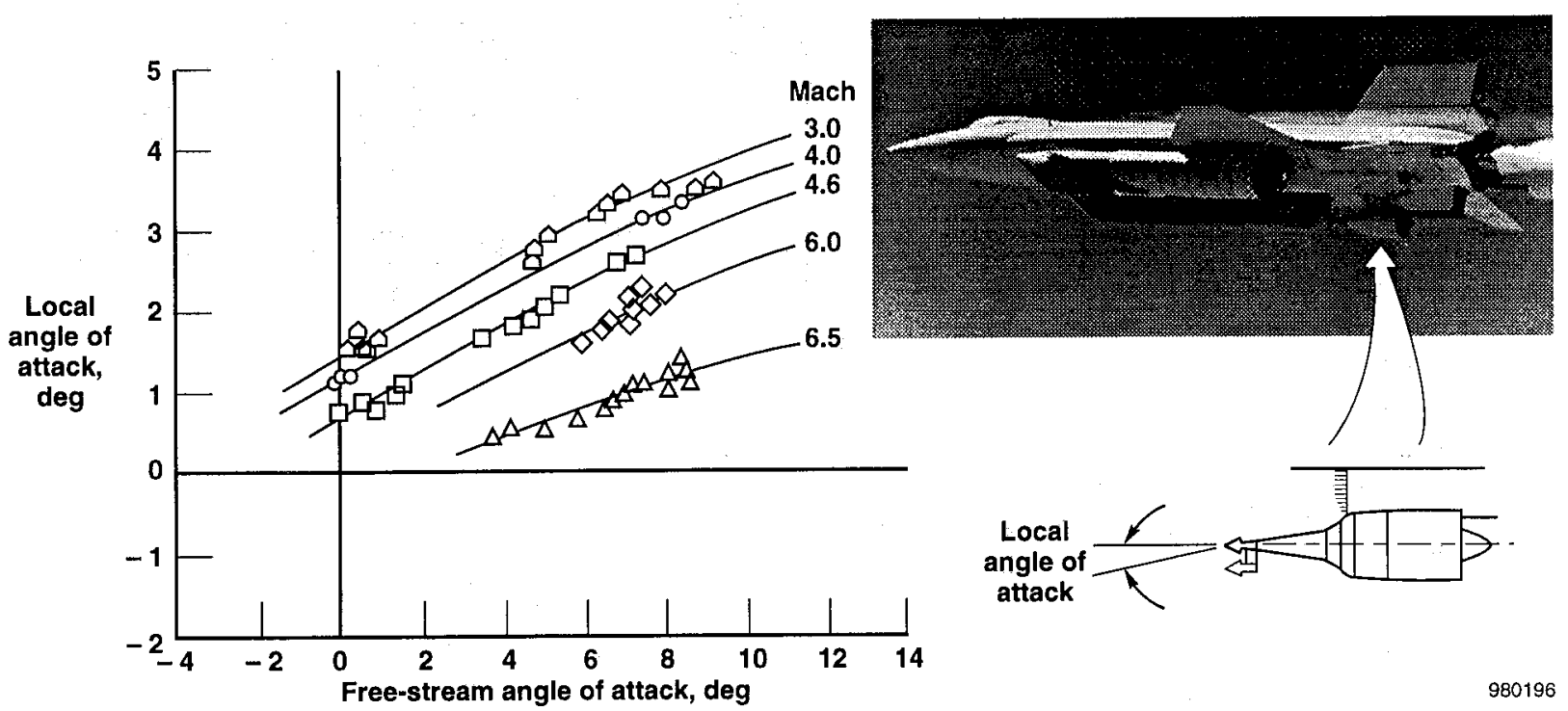

Figure 3. A local flow angularity at the dummy ramjet spike tip, X-15 flight data. ${ }^{3}$

intervening 30 years, many projects have been established to test scramjet engines in flight, but none have flown in the United States. The Hyper-X vehicle, discussed later, is planned to fly in the next century.

\section{Acoustic Tests in the 1960's}

During the XB-70 ground thrust evaluation tests, acoustic measurements of the exhaust and inlet radiated noise were made. These measurements included the effects of engine spacing as well as thrust levels. Takeoff noise measurements on the XB-70 airplane were made. Sonic boom measurements were made using the XB-70 airplane and using the X-15 vehicle with the rocket engine on and off.

\section{The F-111A Instantaneous Inlet Pressure Distortion}

The F-111A airplane, first flown in the early 1960's, represented a major step in multimission airplane design. The propulsion system featured a variablegeometry inlet close-coupled to an afterburning turbofan engine exhausting through a blow-in-door ejector nozzle. Initial flight tests showed problems that had not been predicted by ground facility tests; these problems threatened the operational use of the airplane. Compressor stalls occurred at steady-state distortion levels lower than anticipated.

In 1967, the number 6 F-111A was delivered to NASA Dryden. NASA Dryden developed an 8-rake, 40-probe, engine face pressure measurement system. Four of the rakes were conventional steady-state pressure rakes; the other four rakes contained miniature transducers closecoupled to probes and recorded the outputs on a pulse code modulation system at 400 samples/sec. The miniature transducers were very temperature-sensitive, and their steady-state pressure levels were totally unreliable. The conventional rake data were used to correct the absolute values of the miniature transducers, and these "instantaneous" pressure data were used to develop instantaneous distortion maps and parameters. High levels of instantaneous distortion that persisted for as few as one fan revolution were found to cause stalls.

Figure 4 shows one of the first flight-recorded time histories of instantaneous distortion causing a stall at Mach 2.17. ${ }^{16} \mathrm{~A}$ peak in distortion is clearly seen $15 \mathrm{msec}$ before the occurrence of stall. Boundary-layer ingestion, high throat Mach number, and separation in the "S-shaped" inlet were found to contribute to the stall problem, which was eventually fixed after several redesigns.

One of the engines flown in the F-111A airplane at NASA Dryden was later taken to NASA Lewis and tested in the Propulsion System Laboratory (PSL). An in-flight pressure nulling system was added to the rakes to obtain reliable steady-state dynamic pressure measurements from miniature transducers; these nulling rakes were flown later at NASA Dryden on the F-111A number 12 airplane. The methodology learned in the F-111A tests was applied to the F-15 inlet design and development; very few inlet problems occurred in the F-15 airplane. 


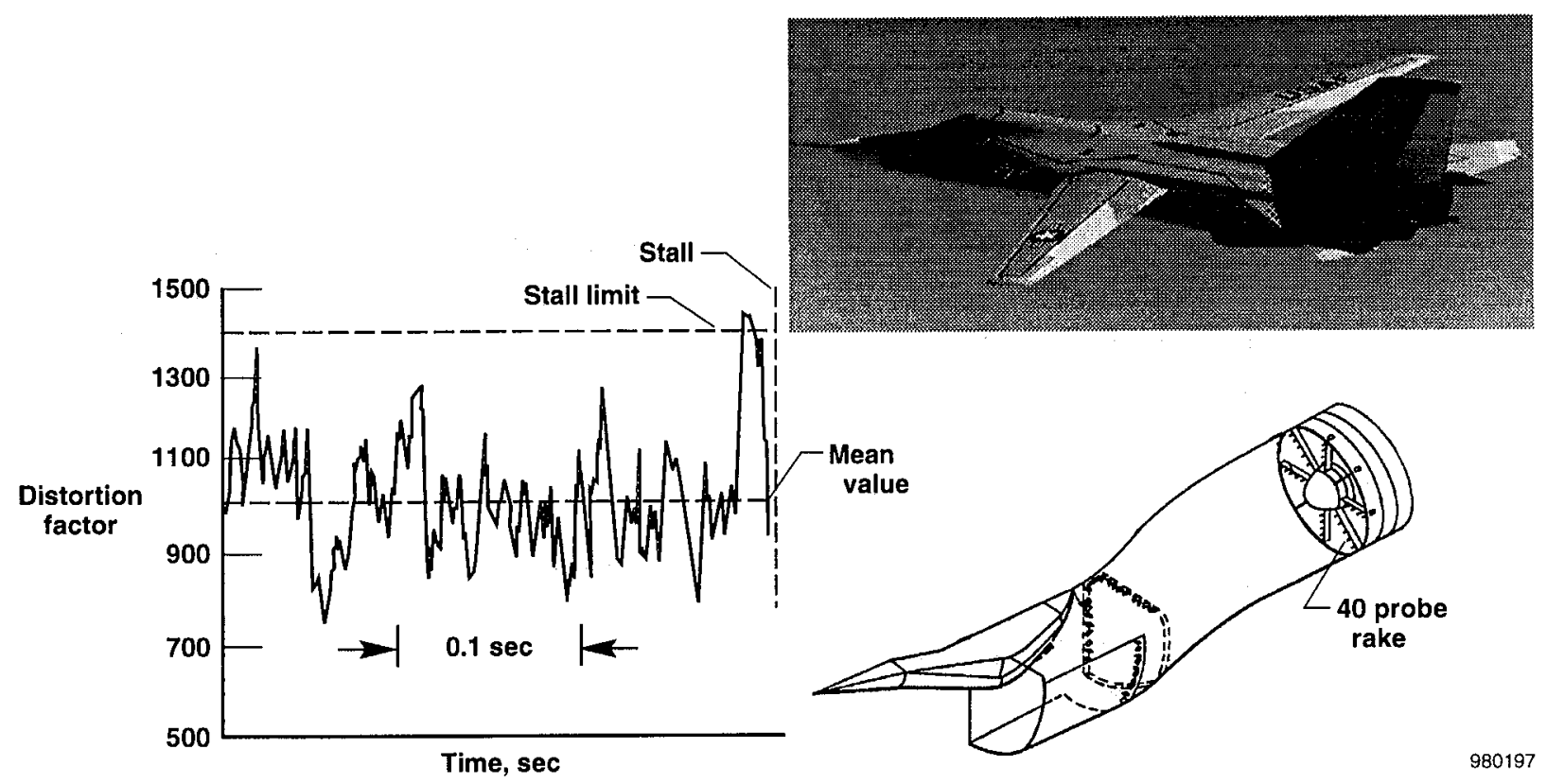

Figure 4. Time history of inlet instantaneous distortion factor leading to fan stall, F-111A airplane, Mach 2.17. ${ }^{16}$

\section{The F-111E Integrated Propulsion Control System}

Because of NASA Dryden's previous F-111A propulsion experience, the United States Air Force (USAF) asked NASA in 1973 to assist in developing and flight-testing a digital IPCS. The IPCS, installed on an F-111E airplane, was the first integrated digital propulsion control system flown. The Boeing Company (Seattle, Washington), Pratt \& Whitney (East Hartford, Connecticut), and Honeywell (Minneapolis, Minnesota), were the major contractors.

The TF30 (Pratt \& Whitney) afterburning turbofan engine had a full-authority digital control and was integrated with the control of the variable-geometry external compression inlet. Controlled variables in the inlet were the translating spike and expanding cone. Controlled variables in the engine were the main and five zones of augmentor fuel, the compressor bleeds, and the nozzle area. The engine control featured two modes: one a digital implementation of the hydromechanical controller; the other a new research digital engine control mode. The controller was remotely mounted in a cooled weapons bay. Significant performance benefits included stall-free operation, faster throttle response, increased thrust, and increased range at a Mach number of $1.8 .^{4}$

The IPCS program achieved its planned objectives on schedule and within budget. The flexibility of the software was used to develop additional capabilities, such as an on-line thrust calculation that had not been planned; and overall, the IPCS program was viewed as more successful than planned. This rather humble beginning led to widely used military and commercial digital engine control technology that has made a major improvement in reliability, maintainability, and engine operability and efficiency. The IPCS program also demonstrated the capability and flexibility of digital engine control technology.

\section{The YF-12 Propulsion Research}

The XB-70 propulsion system was not suitable for an SST, but another supersonic cruise airplane, the YF-12 airplane, had a propulsion system similar to that proposed for the SST. The YF-12 and SR-71 series airplanes featured for each duct propulsion system a single engine that had a relatively short and lightweight mixed-compression axisymmetric inlet, an afterburning turbo-ramjet engine, and a blow-in-door ejector nozzle.

Propulsion system characteristics were studied in a comprehensive wind tunnel-to-flight program to establish the validity of wind-tunnel tests at various model scales. One-tenth-scale, one-third-scale and fullscale wind-tunnel tests were run, including tests of an actual SR-71 inlet nacelle in the NASA Lewis $10 \mathrm{ft}$-by$10 \mathrm{ft}$ tunnel. One of the J58 (Pratt \& Whitney, West Palm Beach, Florida) flight engines was calibrated in the PSL at NASA Lewis. 
In flight, measurements of bleed and bypass flows, inlet dynamics, airflow, and distortion were made at speeds to a maximum of Mach 3.2. The dynamic loads, forces, and moments of inlet "unstarts" are of major concern for an SST. Figure 5 shows one example typifying static pressures through the inlet during an intentional inlet unstart. Prior to the unstart, which was initiated by slowly closing the inlet bypass, the cowl throat static pressure increased and its dynamics decreased as the terminal shock moved upstream into the throat. When upstream of the throat, the shock was unstable and moved rapidly out upstream of the cowl into the unstarted condition; the disturbance propagated all the way forward to the spike tip. Pressure recovery fell drastically at the compressor face, and unsteadiness is also evident in the trace. The inlet restarted $0.5 \mathrm{sec}$ later as the spike and bypass moved to the restart position. Many similar unstarts were induced over the flight envelope.

The forces and moments associated with the propulsion system bypass flows were quite large. At high speeds, the propulsive rolling and yawing moments were, over the lower linear range, more powerful than the ailerons and rudders.

One primary requirement for the YF-12 research was to develop instrumentation that could withstand the high temperatures associated with supersonic cruise.
The inlet temperatures were as high as $800^{\circ} \mathrm{F}$ and engine bay temperatures were near $1000^{\circ} \mathrm{F}$. Eddy current displacement transducers had to be developed that were small enough to install in rakes for making dynamic pressure measurements. A fluidic turbine inlet gas temperature sensor was also developed and evaluated. Most of the results of the propulsion research on the YF-12 airplane are summarized in previous publications. ${ }^{7,17}$

\section{The YF-12 Cooperative Control}

In 1973, NASA Dryden began conducting autopilot and inlet control system tests on the SR-71 and YF-12 airplanes. In the late 1970's, after the success of the F-111E IPCS project, another control integration experiment was initiated. Several of the separate analog and mechanical control systems of the NASA YF-12 research airplane were replaced with a cooperative digital control system. All functions of inlet control, autopilot, autothrottle, airdata, and navigation systems were performed in a single digital computer. The central digital computer control provided more accurate and faster response computations than separate analog/ mechanical control systems. Airdata computations were improved, and lag compensation was applied. ${ }^{5}$ In addition, more precise inlet control was obtained with the digital system, and inlet stability margins were reduced. The overall result of the flight research was that range was increased by 5 percent. Altitude control

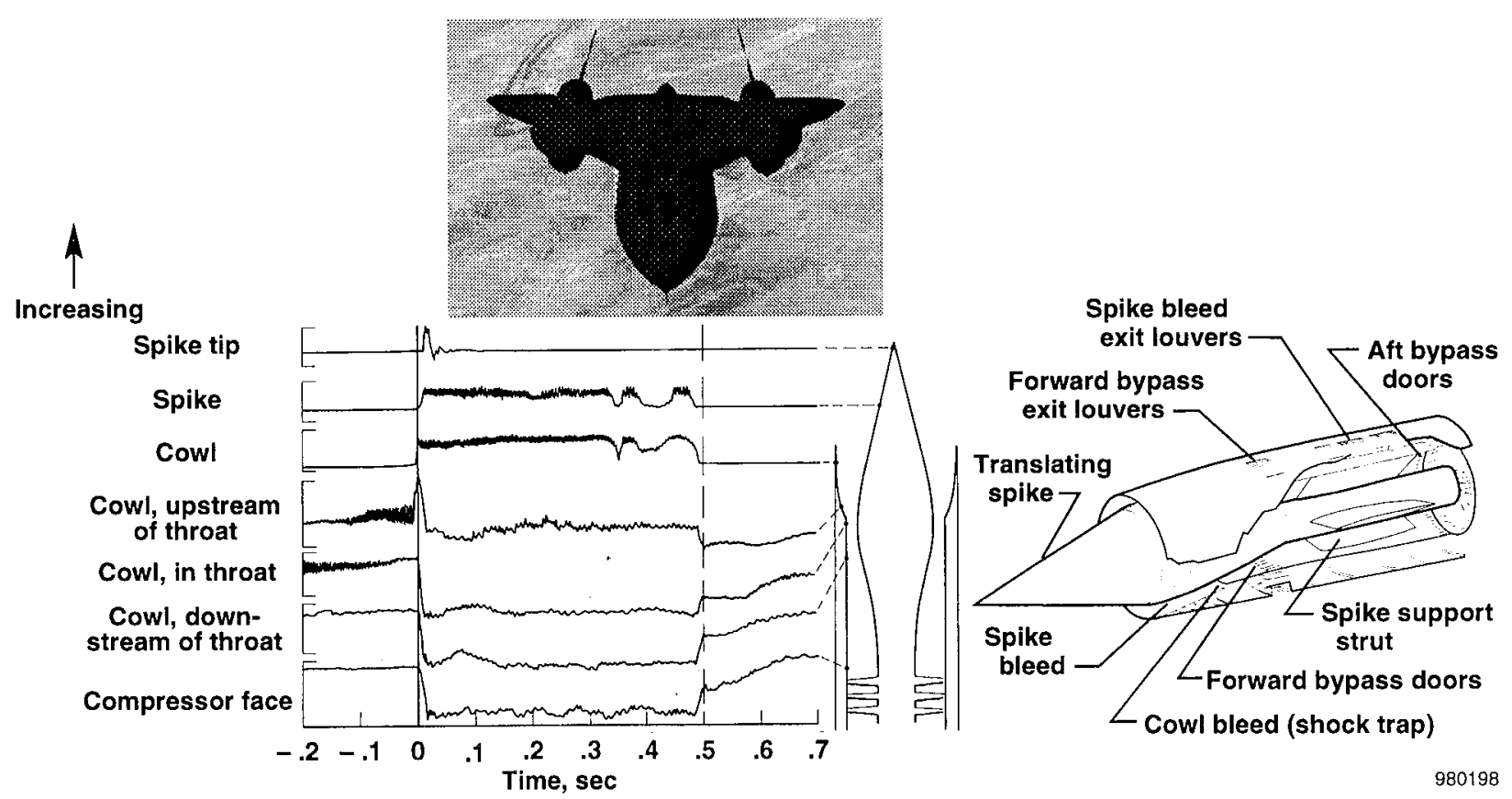

Figure 5. Time history of inlet unstart and restart static pressures, YF-12 inlet, Mach 2.5. ${ }^{17}$ 
capability was improved by an order of magnitude as compared to manual control. ${ }^{17}$

Based on the success of the digital flight and propulsion control system on the YF-12 airplane, the SR-71 fleet incorporated the cooperative control system concepts as part of a major avionics upgrade. In fleet use, this system realized range improvements of 7 percent, reduced thrust degradation during turns, and essentially eliminated the occurrence of inlet unstarts. Thus, the flight demonstration served to speed the transition of the technology developed during the YF-12 flight and propulsion control research to the operational SR-71 fleet. ${ }^{17}$

\section{Acoustic Tests in the 1970's}

Several acoustic tests were conducted in the 1970's at NASA Dryden. Airplanes were flown with engines at idle or completely off over microphone arrays to measure the nonpropulsive "airframe" noise. The JetStar and Aerocommander airplanes were flown with power off; the B-747, B-727, and CV-990 airplanes were flown with engines at idle. ${ }^{20}$ The wide speed range flown on the JetStar airplane enabled a correlation of airframe noise with the fifth power of aircraft velocity. Flyover tests of business jets were also conducted to determine the effects of modified approach procedures on approach noise. $^{21}$ Acoustic characteristics of the F-111E exhaust and inlet radiated noise were also measured in static tests. At the conclusion of the F-111E IPCS program, the digital control system was used to recontour the engine exhaust profile, and flyover acoustic tests were conducted. $^{22}$

Static acoustic measurements and sonic boom tests on the YF-12 airplane were also conducted. At the end of the YF-12 propulsion program, detailed internal inlet measurements were correlated with static acoustic measurements to quantify the noise reduction associated with choking of the inlet flow. Contrary to predictions, forward-radiated noise reductions were obtained at throat Mach numbers well below choking, which implies that controlling SST approach noise will be easier than previously thought.

\section{$\underline{\text { F-15 Propulsion Flight Research }}$}

In 1976, a joint NASA-USAF research program was developed to explore the predictability of propulsion system and aircraft integration drags using techniques intended to eliminate problems seen in the F-111 design. The USAF loaned two F-15 airplanes and four test engines to NASA for flight research. A comprehensive flight, wind-tunnel, and analysis project was conducted on inlet, engine, and exhaust nozzles of the F-15 series airplanes. The F-15 number 2 (the propulsion test airplane) and F-15 number 8 (the high-angle-of-attack test airplane) were used for the tests.

Two of the F100 test engines, P680059 and P680063 (Pratt \& Whitney), were calibrated in the PSL at NASA Lewis. Highlights included the flight measurement of inlet dynamic distortion, inlet drag, thrust calculation using several methods, nozzle aft-end integration, and nozzle acoustics. Most test results as of 1985 were summarized in a previous publication. ${ }^{8}$ Flight-toground facility predictions agreement was generally good. One discrepancy was found in the aft-end drag assessment. This assessment used wind-tunnel data taken with faired-over inlets, which altered the aft-end boundary-layer characteristics and resulting nozzle boattail pressures. The F100 engine, P680063, continued tests in various configurations and research projects in the F-15 airplane until $1994 .^{23}$

\section{Highly Maneuverable Aircraft Technology Propulsion $\underline{\text { Research }}$}

The HiMAT project flight-tested advanced technologies on a remotely piloted, scale vehicle. Technologies included an aeroelastically tailored composite supercritical wing, close-coupled canard, digital fly-by-wire flight control system with relaxed static stability, winglets, and an integrated flightpropulsion control system. The propulsion system was a J85-21 (General Electric, Lynn, Massachusetts) engine. In-flight thrust calculation and engine-flight control integration tests were performed. ${ }^{22}$

\section{The F-14 Engine-Inlet Compatibility}

Testing at NASA Dryden was conducted to study the ability of advanced aileron-rudder interconnect logic to improve the departure resistance of the F-14 airplane. During these tests at extreme angles of attack and sideslip, numerous compressor stalls occurred as a result of high levels of inlet distortion. The propulsion task was to detect engine stalls and advise the pilot on the needed action to manage the engines during the departure tests. More than 90 stalls occurred, but no engine damage occurred and the pilot recovered successfully in all cases. ${ }^{24}$ The aileron-rudder interconnect logic has been incorporated into the digital flight control upgrade on the F-14 airplanes.

\section{The F-15 Digital Engine Electronic Control System}

After the success of digital engine control technology developed in the IPCS program, the engine manufacturer 
developed a "production-quality" digital electronic engine control (DEEC) system for the F100 engine. NASA Dryden agreed to conduct an early flight evaluation of the DEEC system on the F-15 airplane. The DEEC system is a full-authority engine control system for the F100 engine. The system controls all of the controlled variables on the engine and replaces the standard F100 engine control system. The DEEC system is engine-mounted and fuel-cooled and consists of a single-channel digital controller with selective inputoutput redundancy and a simple hydromechanical secondary control.

Flight testing began in 1981 using the F-15 airplane, and continued into 1983 in four separate phases. During the flight evaluation, NASA Dryden worked closely with the USAF and the engine manufacturer, and several problems were found. The most significant was a nozzle instability that occurred during afterburning conditions at high altitude. This instability caused stalls and blowouts and was not predicted by simulations or altitude facility tests. The instability was thoroughly investigated by using a NASA Dryden-developed nonlinear simulation to analyze the problem and conducting tests in the PSL at NASA Lewis, and was eventually eliminated with control system changes. By the end of the NASA Dryden and NASA Lewis tests, significant improvements had. been demonstrated, including stall-free operation over the entire F-15 flight envelope, faster throttle response, improved air-start capability, and an increase of more than $10,000 \mathrm{ft}$ altitude in afterburner operation with no pilot restrictions on throttle usage.
Figure 6 shows the DEEC idle-to-maximum power throttle transient results after each test phase. After phase four, all these transients were successful, whereas the F100-PW-100, without the DEEC, would experience stalls and blowouts above the indicated boundary. ${ }^{25}$ The "nonthreatening NASA environment" fostered identifying and fixing DEEC problems on a timely basis.

The successful completion of the NASA DEEC test program allowed the USAF to elect to put the DEEC system into full-scale development and production. During the same time period, an evaluation was initiated for the F-16 airplane that was equally successful. The DEEC-equipped engines have become the production and retrofit standard for F-15 and F-16 airplanes and have demonstrated large improvements in performance, maintainability, and reliability. The USAF credited the early NASA flight investigation of DEEC with accelerating the introduction of the DEEC system by $1.5 \mathrm{yr}$, thus saving millions of dollars. The NASA, USAF, and contractor flight evaluation in the F-15 airplane was responsible for transitioning the DEEC technology quickly into operational use.

\section{The F100 Engine Model Derivative}

After the successful DEEC tests, Pratt \& Whitney and the USAF brought an upgraded F100 engine to NASA Dryden in 1983 for flight test. The engine upgrades developed through the USAF engine model derivative (EMD) program included a new fan, a new 16-segment augmentor, single-crystal turbine blades and vanes, and an improved DEEC system. The USAF developed

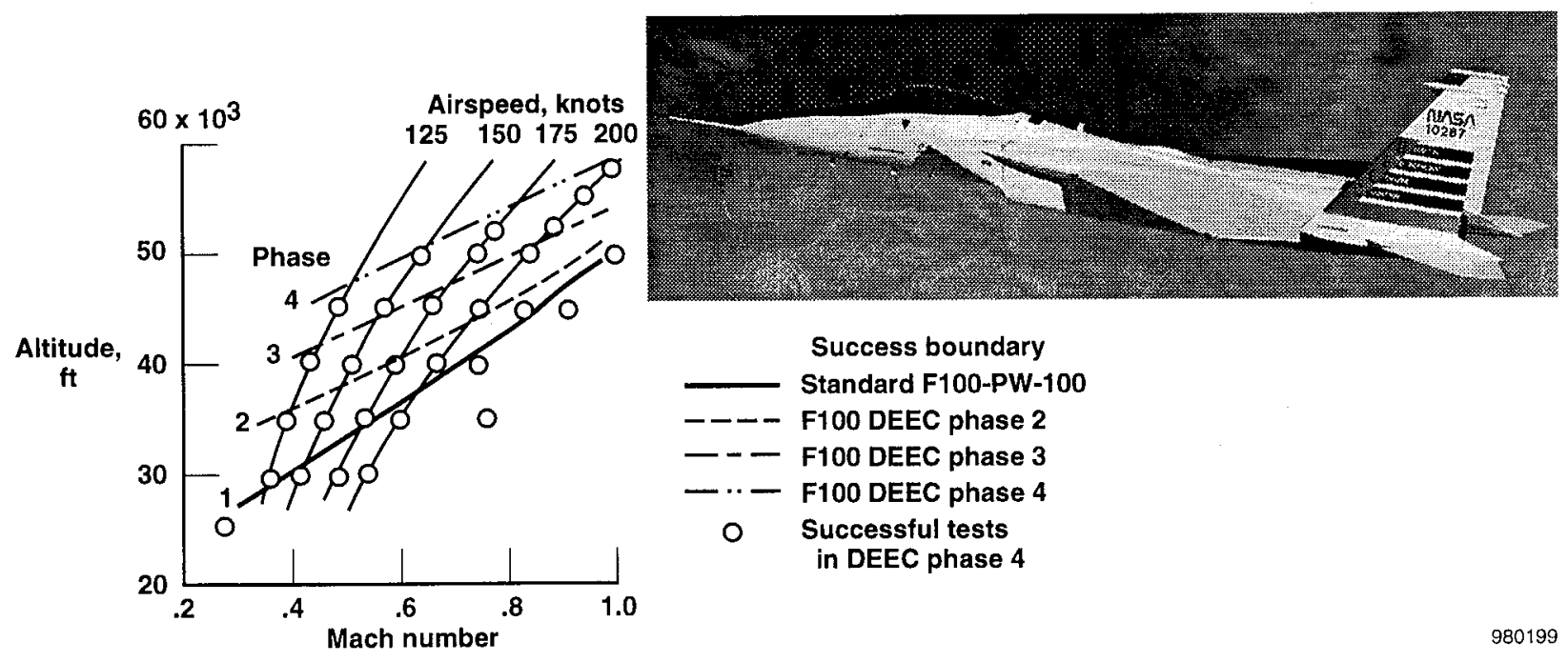

Figure 6. Improvement in idle-to-maximum power throttle transient success, DEEC-equipped F100 engines in NASA F-15 airplane. ${ }^{25}$ 
the F100 EMD in conjunction with Pratt \& Whitney (company designation PW1128) and formulated a joint program with NASA Dryden to conduct a flight evaluation.

The F100 EMD had approximately 15 percent more thrust than the standard F100 engine; this additional thrust improved F-15 performance significantly. In the F-15 airplane, the time to accelerate from Mach 0.8 to Mach 2.0 was reduced by 25 percent. The airplane also gained dry-power supersonic cruise capability (Mach 1.15) at intermediate power with F100 EMD engines.

The 16-segment augmentor that replaced the 5-segment augmentor of the F100 exhibited improved operation. Smaller pressure pulses associated with the more numerous segments completely eliminated augmentor-induced stalls during the flight evaluation.

While conducting the flight evaluation, compressor stalls were encountered during intermediate-to-idle power throttle transients at very high-altitude, lowairspeed conditions. These stalls were not predicted by analytical or altitude facility results. Special highresponse pressure probes were installed at the fan discharge, and the resulting data showed that under certain conditions, flow separation occurred that increased the distortion to the compressor. Why altitude facility results could not duplicate the flight results was not clear. The NASA Dryden analysis showed the flow separation to be a function of the ratio of core to fan speeds. A control modification that slowed engine response was implemented to fix the problem. ${ }^{1}$ Based on the analysis, the intermediate case diffuser was later redesigned and now provides rapid and stall-free operation for the F100-PW-229 engine.

A throttle response problem was also found when the test pilots tried to fly formation in airplanes using F100 EMDs. Added lag for bodie throttle transient protection resulted in unacceptable formation flying qualities. ${ }^{1}$ When found, this problem was fixed with a software change. The generic engine response problem was caused by lack of criteria for acceptable throttle response, which was then addressed with another flight experiment, as discussed later.

\section{The F-15 Highly Integrated Digital Electronic Control Modes and Results}

With the successful development of the DEEC and installation of a digital electronic flight control system on the F-15 airplane, integrating the engine and flight control systems became practical. The HIDEC program integrated these systems and developed several control modes to make use of the integrated system capability. These control modes and the flight results are discussed in the following sections.

\section{Adaptive Engine Control System}

As part of the HIDEC program, an adaptive engine control system (ADECS) mode was incorporated on the F-15 airplane. In this mode, airframe and engine information was used to allow the engine to operate at higher performance levels at times when the inlet distortion was low and the full engine stall margin was not required. This mode increased thrust levels by increasing engine pressure ratio (EPR) at constant airflow (EPR uptrim). Fuel flow reductions were also obtained by reducing the throttle setting to hold thrust constant as EPR was increased. In essence, the ADECS trades excess stall margin for improved performance.

During flight evaluations, the system was evaluated on the F100 EMD engines in the F-15 airplane and significant performance improvements were demonstrated. The ability of the ADECS to adapt to rapid aircraft maneuvers and throttle transients was also demonstrated. Intentional stalls were also conducted to validate the stability audit procedures used to develop the ADECS logic.

Figure 7 shows typical results. The calculated intermediate (military) power thrust was increased by 8-10 percent. Fuel flow reductions obtained at maximum afterburning thrust levels with the power lever angle reduced to hold constant thrust are shown decreased by $7-17$ percent. These engine performance improvements resulted in airplane performance improvements (rate of climb, specific excess power) of $10-25$ percent at maximum afterburning power.

\section{Extended Engine Life Mode}

The extended engine life mode increases engine life by reducing turbine temperature. This reduction is accomplished by increasing EPR while decreasing engine airflow along a line of constant thrust, which reduces fuel flow and temperature by $10-80^{\circ} \mathrm{F}$. These types of temperature reductions were used to predict a 10-to-12-percent extension of engine hot section life by the engine manufacturer.

\section{Inlet Integration}

Another HIDEC integrated control mode included control of the inlet and was flown in 1989. Inlet cowl and 

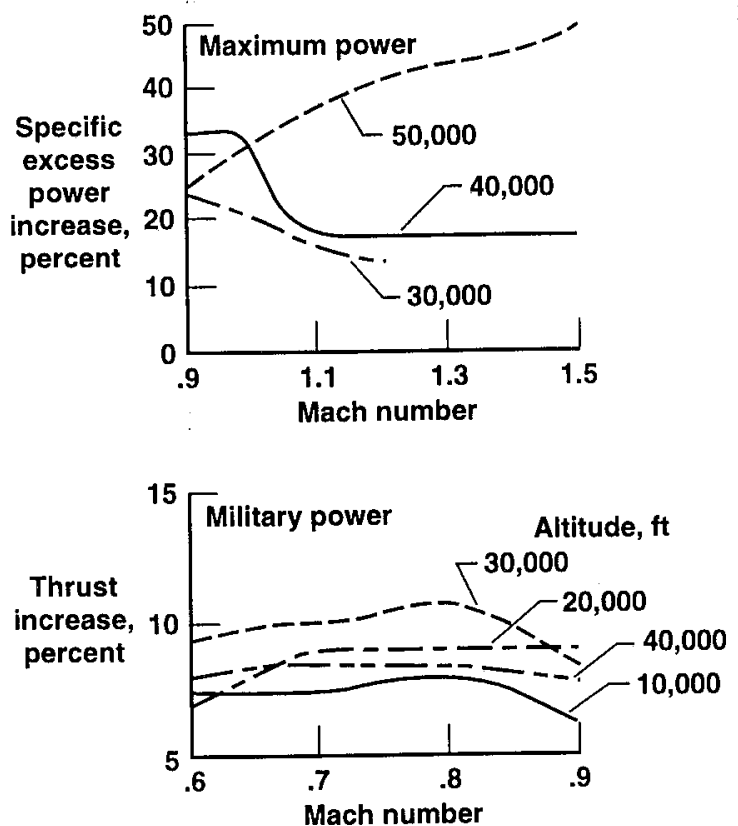

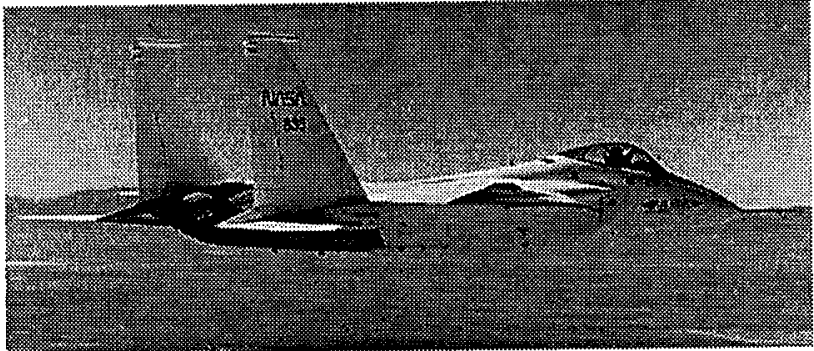

Reduction in fuel flow with uptrim to obtain nonuptrimmed maximum thrust

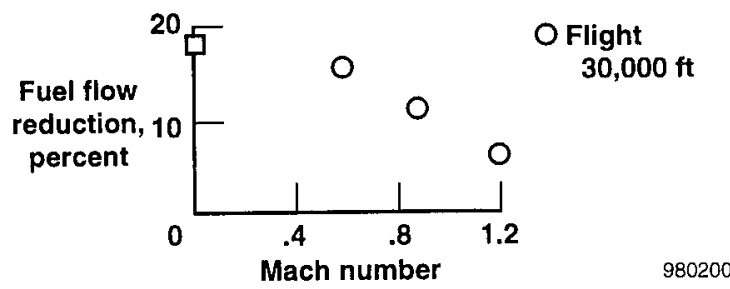

Figure 7. HIDEC performance, thrust, and fuel flow improvements, F-15 airplane. ${ }^{6}$

ramp angles were biased from their normal schedules as a function of engine airflow, and small performance benefits were realized. In addition, the inlet cowls have an airplane pitching moment influence that was used to reduce the horizontal tail trim drag, thus reducing the overall airplane drag. This practice was the first time inlets were used to reduce the drag of flight control system surfaces.

\section{Highly Integrated Digital Electronic Control} Technology Transfer

Portions of the HIDEC technology have been incorporated in the F100-PW-229 increased performance engine (IPE) and in other advanced engines. The inlet integration concept is now included in SST designs. The flight demonstration and evaluation performed at NASA Dryden were instrumental in the rapid transition of HIDEC technology into operational use. Results of the HIDEC program have been summarized in a previous publication. 6

\section{Performance-Seeking Control}

Performance-seeking control (PSC) was a program that featured an onboard real-time adaptive optimization of engine, inlet, and airplane parameters on the F-15 airplane. The previously discussed HIDEC modes were developed off-line using extensive mathematical models of the engine and airplane. The schedules of optimum EPR were stored onboard in tabular form as a function of the flight and engine variables. As such, the
HIDEC EPR uptrim schedules were only optimum for the average engine operating with nominal bleed on a standard day.

Conversely, PSC uses many measured parameters to optimize the performance in real time on board the airplane. A Kalman filter was also used by PSC to identify in near-real time key engine parameters, which were then used to update the engine model. In this way, the engine model could adapt to the actual engine and flight conditions being flown.

Performance-seeking control developed and implemented modes similar to the HIDEC modes, but with higher performance. Flight tests were flown with the Kalman filter on and off to determine the effects of engine model update technology. The onboard engine model was very successful. The engine manufacturer now uses the self-tuning onboard engine model in their advanced engine controllers, including the controllers on the F119 engine used to power the F-22 airplane.

The minimization of thrust can also be important for flight modes such as an emergency descent. A minimumthrust mode was developed and flown that operated the engine and the inlet in the maximum-drag, minimumthrust mode. ${ }^{23}$ Another control mode of interest for some military applications is a minimum-exhaust temperature mode. Performance-seeking control proved capable of implementing these modes. More details of 
the PSC implementation and flight results on the F-15 airplane have previously been published. ${ }^{26,27}$

The system architecture for the HIDEC and PSC programs was founded on the single-channel fail-safe philosophy. These integration concepts were designed so that the pilot could immediately turn off any control mode and return to the normal control modes. This design allowed resources to be concentrated on control mode research and evaluation and not on redundancy management and detailed hazard analysis. This philosophy was possible on the F-15 airplane because of the independent mechanical flight control system and allowed a great deal of flexibility without the cost and schedule impacts of fault-tolerant systems.

\section{Controlled Impact Demonstration}

In 1983, NASA and the Federal Aviation Administration conducted the controlled impact demonstration (CID) test. A B-720 airplane was modified for remote piloting and intentionally crashed on the dry lakebed. Experiments included crash loads, fire blocking, and AMK. The AMK was created by adding additives to jet "A" fuel to reduce its tendency to form an explosive mist upon impact. In order to burn this fuel in the standard JT3-C6 engines (Pratt \& Whitney), degraders were developed to cut the long-chain polymers of the fuel before the fuel entered the fuel control and fuel spray nozzles. The degraders were powered by engine-bleed air. Propulsion engineers at NASA Dryden worked with the degrader manufacturer and NASA Lewis to develop, instrument, and flight-test the degraders. Although the degraders operated successfully, the AMK fuel was found to provide inadequate protection for the crash. After impacting the ground, one of the engines hit an angle-iron wing cutter, causing this engine to disintegrate. This exploding engine provided a very severe ignition source that the fuel additive did not suppress. Valuable crash loads data were obtained, however. ${ }^{13}$

The actual flight test of AMK was extremely valuable in preventing premature incorporation of AMK into commercial aviation. Many problems might have occurred as a result of AMK clogging fuel systems or fuel degrader failures; these problems could have significantly overshadowed any benefits from the possible suppression of crash fires.

\section{Throttle Response Criteria}

The thrust response to throttle movement can be important for formation flying and aerial refueling. In the late 1980's, a throttle response experiment was performed on a NASA Dryden F-104 airplane. For this experiment, the excellent response of the $\mathrm{J79}$ (General Electric, Evendale, Ohio) engine could be systematically degraded by using an electronic box in the cockpit, adding time delay, lag, or rate limits. Pilot CooperHarper ratings were obtained to determine the effects on close-formation handling qualities.

Figure 8 shows results of time delay. As time delay increases, pilot ratings get worse, with unacceptable ratings for time delays greater than $0.35 \mathrm{sec}$. Other data not shown showed that rate limiting was a factor at rate limits of less than $40 \mathrm{deg} / \mathrm{sec}$, and was unacceptable at less than $20 \mathrm{deg} / \mathrm{sec}$. This first quantification of these effects is summarized in a previous publication. ${ }^{28}$

\section{The F404 Engine Performance}

To support the vehicle performance determination of the X-29 Advanced Technology Demonstrator during the mid 1980's, several in-flight thrust calculation methods were used and evaluated. ${ }^{11} \mathrm{~A}$ real-time thrust measurement technique ${ }^{29}$ was developed from calibration data obtained during altitude facility tests conducted at NASA Lewis. This method required less instrumentation and computational power and was determined to have a 1.8-percent accuracy. A real-time aeroperformance technique was also developed on the F404-equipped X-29 to provide near-instantaneous evaluation of flight test maneuver technique and data quality. The capability to calculate and display performance data for real-time monitoring increased flight productivity by providing the information to determine whether repeat test points were required during the flight.

The F/A-18 HARV, also powered by F404 engines, began flying in the late 1980's. The F/A-18 HARV also employed several in-flight thrust calculation methods (including the real-time thrust measurement technique) to evaluate engine performance during extreme maneuvering.

A performance thrust-modeling technique developed under a grant to the University of Kansas generated aircraft and propulsion system performance models of an airplane without actually measuring engine thrust. These models were found to be accurate to within \pm 5 percent and $10 \mathrm{drag}$ counts. These methods have been used to generate models for flight training simulators that fly very much like the airplane modeled. ${ }^{30}$ 


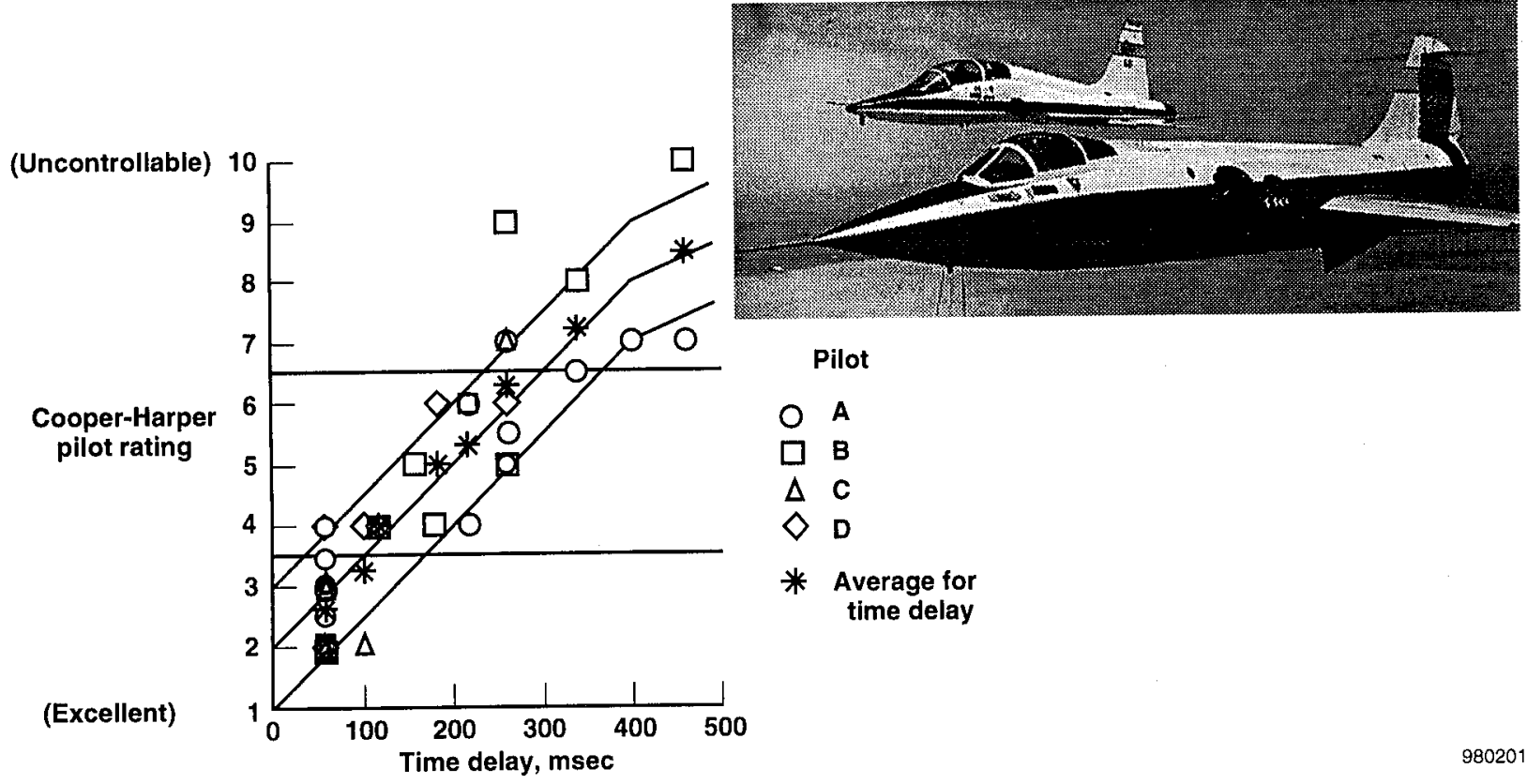

Figure 8. Effect of time delay on close-formation handling quality ratings, F-104, $300 \mathrm{kn}$, an altitude of $15,000 \mathrm{ft}^{28}$

\section{Acoustics Research in the 1980's}

In the early 1980 's, NASA Dryden conducted a static test of twin-jet exhaust noise in support of the NASA Langley Research Center (Hampton, Virginia). Cracks had been observed developing in closely-spaced nozzles in the F-15 and B-1 airplanes. NASA Langley anechoic chamber test data needed full-scale evaluation test data for validation. Later, another test was done in flight, and acoustic, pressure, and strain measurements were made on the nozzle flaps. ${ }^{23}$

Acoustic tests were also done to support the development of prop fans. Two-foot-diameter models of three advanced prop fans (APFs) were mounted atop the JetStar airplane, and microphones were located along the fuselage surface. Data were collected over a range of flight conditions, and far-field measurements were made by the NASA Lewis Learjet airplane. NASA Dryden also measured the fuselage boundary layer in the APF region on the upper fuselage.

\section{Thrust-Vectoring Research}

The F/A-18 HARV employed a special nonproduction-quality, multiaxis thrust-vectoring system consisting of three paddles mounted asymmetrically at the exhaust plane of each nozzle. An extensive ground test of the multiaxis thrust-vectoring system installed in the aircraft was conducted on the Edwards AFB thrust stand before its first flight. Results of
98020 evaluating the measured axial thrust loss caused by vectoring validated subscale cold-jet predictions developed at NASA Langley. ${ }^{9}$

A research grant with California Polytechnic State University at San Luis Obispo (Cal Poly) was established during the F/A-18 HARV program to support research of the thrust-vectoring system. Cal Poly developed a subscale cold flow facility with two independently controlled nozzles to evaluate the interaction of the two jets during vectoring and the plume impingement concerns raised during ground testing. Cal Poly also developed a color Schlieren video system and an accurate six-axis force balance to provide unique research data complementary to flight results.

The X-31 airplane employed a multiaxis thrustvectoring system with paddles on its single $\mathrm{F} 404$ engine. The Cal Poly facility was employed by the X-31 program to expand the thrust-vector range of the paddles from $25^{\circ}$ to $35^{\circ}$. A primary aspect of this research included instrumenting the nozzle model with pressure measurements to assure engine stability was adequate at the extreme deflection angle.

Research is currently being conducted on two production-like multiaxis thrust-vectoring nozzles installed in the F-15 Advanced Control Technology for Integrated Vehicles (ACTIVE) airplane equipped with F100-PW-229 engines. These nozzles, which were derived from the production balance-beam nozzle 
design, use fewer parts, allow independent control of nozzle area ratio, and promise improved vectoring performance over the paddle systems employed on the F/A-18 HARV and X-31 airplane. Results are discussed later.

\section{The F/A-18 High Alpha Research Vehicle Inlet Research}

The influences of high-angle-of-attack and -sideslip flight on aircraft inlet aerodynamic characteristics were investigated as part of the F/A-18 HARV program. The thrust-vectoring capability of the aircraft provided an unique opportunity to obtain quality inlet data at extreme aircraft attitudes and during very high maneuver rates. The right inlet and engine were highly instrumented. A newly developed, 40-probe, total-pressure inlet rake was installed directly ahead of the engine. High-frequencyresponse instrumentation was installed to monitor inlet and engine operation and behavior.

An extensive, high-quality inlet database was obtained for the F/A-18 HARV. Inlet data obtained at speeds of Mach 0.3, angles of attack of $30^{\circ}$, and angles of sideslip of $0^{\circ}$ showed excellent repeatability. During steady aerodynamic conditions, inlet recovery and peak circumferential distortion increased as angle of attack increased and as angle of sideslip became more negative (nose right). ${ }^{31}$ During rapid maneuvers, verification was made that at a given flight condition, inlet distortion levels are less than at an equivalent steady aerodynamic condition (fig. 9). The rapid angle-of-attack maneuver results are significant because how inlet distortion characteristics, obtained during rapid angle-of-attack maneuvers, would compare with distortion obtained during steady aerodynamic conditions was unknown. The current practice for evaluating inlet and engine compatibility is by wind-tunnel testing at fixed aerodynamic conditions over a finite time span. Windtunnel test configurations are constrained by fixed model position, limited angle-of-attack range, and limited attitude rate and maneuvering capability.

Twelve intentional aircraft departures were conducted to obtain inlet data prior to and during engine stalls. The magnitude of the peak time-variant total-pressure distortion levels was determined to be well beyond those encountered in the normal engine operating envelope. An unexpected result was that all of the engine stalls that occurred during the departures were initiated in the compressor, not the fan. Inlet distortion predicted using computational fluid dynamics (CFD) compared with flight data shows that the prediction of the average total pressure recovery at low angle of attack was within 1 percent of the flight test data. At high angle of attack, the predicted recovery patterns were significantly different. Based on the study of five airflow estimation methods, a speed-flow relationship may provide the best airflow estimate for a specific engine under all flight conditions.
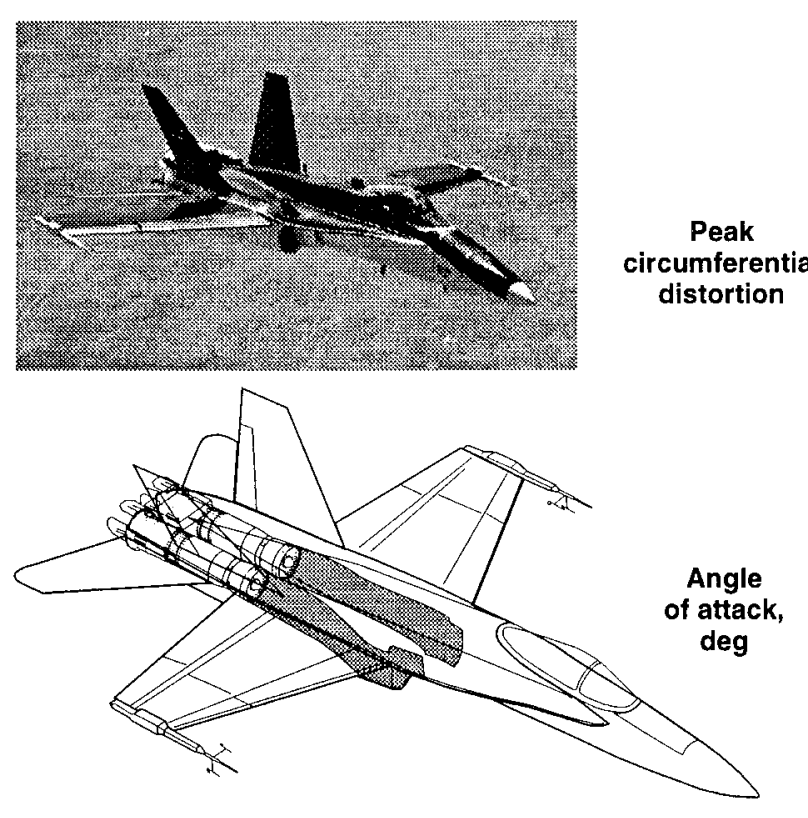

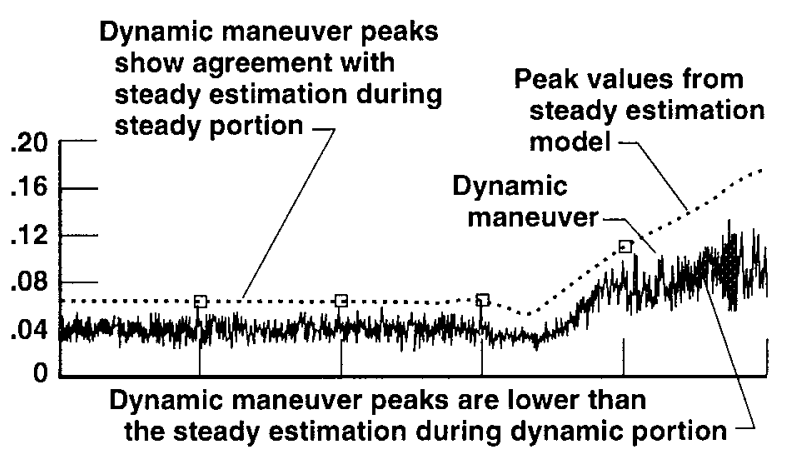

Figure 9. Peak distortion at steady and dynamic angle of attack from $10^{\circ}$ to $60^{\circ}$, F/A-18 HARV. 


\section{The F110-GE-129 Engine Evaluation}

In 1991, NASA Dryden flew the F110-GE-129 IPE in F-16XL number 2. Objectives of the test were to evaluate a new software release for the digital engine controller. Steady-state performance, throttle transients, and air-start tests were performed. The air starts were conducted adjacent to Rogers Dry Lake (Edwards AFB, California). In case a successful air start did not occur, a power-off landing could be made on one of the lakebed runways. All tests were successful, either on the initial test point or on a higher-airspeed air-start attempt.

\section{Propulsion-Controlled Aircraft}

In the past 25 years, a minimum of 10 aircraft, including B-747, L-1011, DC-10, B-52, and C-5A aircraft, have experienced major flight control system failures. The crews tried to use engine thrust for emergency flight control. In most cases, a crash resulted; the B-747, DC-10, and C-5A crashes claimed more than 1200 lives.

With the advent of digital engine control systems, considering the use of engine thrust for emergency flight control became feasible. To investigate this possibility, NASA, Department of Defense, industry, and university researchers began conducting flight, ground simulator, and analytical studies in 1990. One objective was to determine the degree of control available with manual manipulation of engine throttles for various classes of airplanes. Tests of this concept have been conducted on simulations of the B-720, B-747, B-727, MD-11, SR-71, MD-90, C-402, C-17, F/A-18, and F-15 airplanes, and in flight on the B-747, B-777, MD-11, T-39, Lear 24, F/A-18, F-15, T-38, and PA-30 airplanes.

The pilots have used differential throttle control to generate sideslip, which results in roll through the dihedral effect. Symmetric throttle inputs were also used to control flightpath. These tests have shown sufficient control capability for all tested airplanes to maintain gross control; both flightpath and track angle may be controlled to within approximately $3^{\circ}$. For all airplanes tested, these studies have also shown that making a safe runway landing is exceedingly difficult using manual thrust-only control. ${ }^{32}$ This difficulty is caused by slow engine response, weak control moments, sluggish airplane response, and difficulty in controlling the oscillatory phugoid and dutch roll modes.

In order to provide safe landing capability, NASA Dryden engineers and pilots have conceived and developed a system that uses only computer-controlled engine thrust, called propulsion-controlled aircraft (PCA), for flight control. A PCA system uses pilot flightpath inputs and airplane sensor feedback parameters to provide appropriate engine thrust commands for emergency flight control.

Initial flight tests in the F-15 airplane showed that manual throttles-only control was much worse than the simulations predicted. Later, the simulation was updated with second- and third-order effects and eventually matched the flight results. ${ }^{27}$ A ground-effect study was also conducted. ${ }^{27}$ The PCA augmented system was evaluated in simulation and flight tests on the F-15 airplane, and actual landings using the PCA system were made in $1993.32 \pi$

Propulsion-controlled aircraft simulation studies have also been conducted at the NASA Ames Research Center (Moffett Field, California) using the advanced concepts flight simulator and the B-747-400 simulator. Hundreds of PCA approaches and landings have been flown by more than 30 government, industry, and airline pilots.

With the success of the F-15 PCA flight program and other PCA simulation studies, the Boeing Company (formerly McDonnell Douglas Aerospace, Long Beach, California), Pratt \& Whitney (West Palm Beach, Florida), Honeywell (Phoenix, Arizona), and NASA Dryden also developed and flight-tested a concept demonstration PCA system for the MD-11 (The Boeing Company, formerly McDonnell Douglas Aerospace, Long Beach, California) transport airplane. This PCA system used only software changes to existing digital systems on the MD-11 airplane and was flown in 1995. In more than 30 hours of flight testing, the PCA system exceeded the objectives, serving as a very acceptable autopilot and performing landings without using any flight controls. Figure 10 shows a time history of a PCA system landing on the MD-11 airplane.

Later tests studied PCA operation over the full flight envelope, in upset conditions, with all hydraulic systems turned off, and coupled to an instrument landing system (ILS) for hands-off landings. Twenty-one pilots flew PCA demonstration flights. The program results have previously been summarized. ${ }^{14}$ Propulsion-controlled aircraft studies have also been conducted on a simulation of the C-17 military transport airplane; successful landings were made using all flap configurations.

\footnotetext{
IIOne of the F-15 PCA test engines, P063, was the same engine originally provided by the USAF for the F-15 program 17 years earlier. $^{23}$
} 


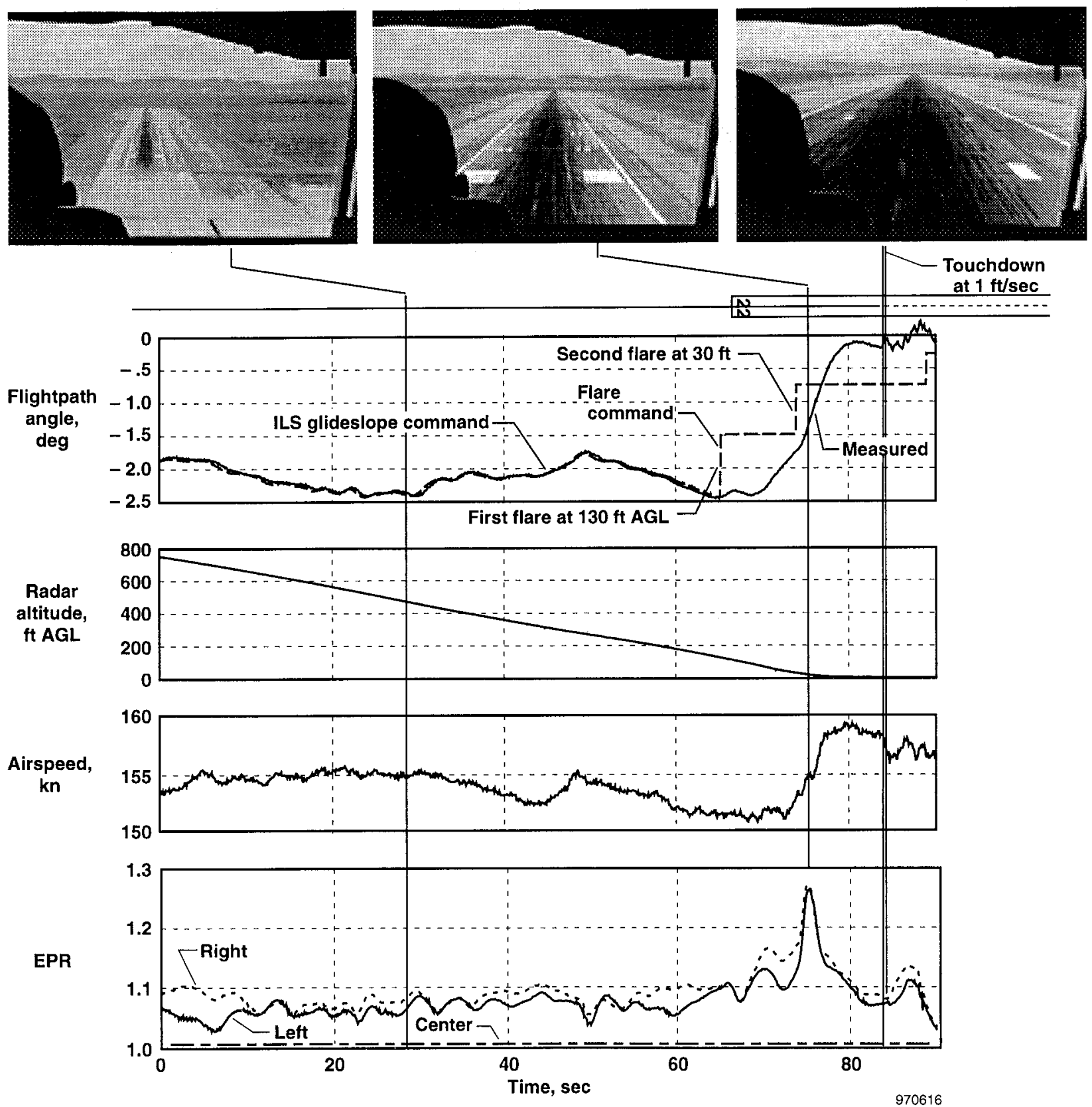

Figure 10. Time history and pilot views of MD-11 propulsion-controlled aircraft system approach and landing, ILScoupled, smooth air, center engine at idle, no flight control movement. ${ }^{14}$ 
Preliminary studies have been conducted on the F/A-18 fighter airplane.

A cost-benefit analysis of PCA technology on a future transport airplane showed cost savings of 140 million dollars for a fleet of 300 airplanes. These benefits accrued from the elimination of a mechanical backup flight control system and the saving of one airplane. The MD-11 PCA flight test was instrumental in validating the technology.

\section{The SR-71 Performance Enhancement}

The NASA Dryden SR-71 research aircraft is currently being used to flight-test a linear aerospike rocket engine in the Linear Aerospike SR-71 Experiment (LASRE) program. The LASRE test payload is a highdrag article mounted to the back of the aircraft, discussed later.

An early objective of the program was to estimate the performance of the SR-71 airplane with the LASRE payload installed. Without adequate excess thrust to accelerate through the transonic-drag rise region, the high-speed LASRE test conditions would be impossible to reach. This early analysis, completed in 1995, predicted the transonic performance to be marginal at best.

To guard against uncertainty in the estimated LASRE payload drag increment, the engine manufacturer was tasked to select a set of top-performing J58 engines for the test program. In addition, these engines were trimmed to the high end of their normal operating band with respect to airflow and exhaust-gas temperature, further improving their performance.

Simulation analyses predicted that these enhanced engines, combined with additional manual exhaust-gas temperature uptrimming during critical portions of the flight and optimized transonic piloting techniques, would provide the additional excess thrust required to attain even the highest speed test condition. Initial flight test results show the performance to be very sensitive to off-standard day temperatures. Additionally, the LASRE payload appears to have more drag than predicted by wind-tunnel testing. After studying the vehicle's actual performance trend with ambient temperature, however, all targeted test conditions to a maximum of Mach 2.0 appear to be attainable during the LASRE program.

The initial analyses were important for determining the feasibility of the LASRE program from a vehicle performance standpoint. The current effort focuses on refining the piloted simulator database using flight data to increase the accuracy of the simulator for test mission planning. ${ }^{33}$

The F-15 Advanced Control Technology for Integrated Vehicles Program

The F-15 number 8 airplane was retired in 1994. The F-15 ACTIVE airplane had been used for the Short Takeoff and Landing (STOL) maneuver program and featured the addition of large canards mounted ahead of the wing and two-dimensional thrust-vectoring and reversing nozzles. The program has developed new aircraft control technologies by integrating a production-quality, full-flight envelope, multidirectional thrust-vectoring system (built by Pratt \& Whitney) into the aircraft control system, first flown in February 1996.

The vectoring nozzle design is based on that of the production F100 nozzle. The addition of a hydraulically driven divergent section actuation system, additional nozzle static structure, and a divergent section synchronization ring permits the nozzle to fully articulate in any direction while simultaneously providing independent exit area control for performance fine-tuning. The new nozzles were designed to produce a maximum of $20^{\circ}$ of off-axis turning, vectoring rates to a maximum of $80 \mathrm{deg} / \mathrm{sec}$, and vectoring forces to a maximum of $4000 \mathrm{lbf}$. To avoid exceeding force limits, vector angles may be further limited by the nozzle controller based on flight condition and throttle setting.

During 1996, the dual-redundant vectoring system was demonstrated at speeds of Mach 2.0, the highest speed achieved with turbine engine thrust-vectoring in aviation history. By the end of 1996, the system had been cleared for use throughout most of the flight envelope of the ACTIVE vehicle, and the flow-turning performance of the nozzle had been mapped through the use of an accurate, strain gage-based, vector force measurement system. The strain-gage system, carefully designed and then calibrated in a ground facility, provides direct axial thrust measurement and off-axis force measurement. Exhaust plume interaction with the airframe during dynamic vectoring was also investigated.

During the summer of 1997, the ACTIVE aircraft successfully flight-demonstrated the high stability engine control (HISTEC) system, developed by Pratt \& Whitney and NASA Lewis. The HISTEC system used real-time engine face pressure measurements in a distortion estimation algorithm to compute and apply EPR debits in order to maintain high engine stability even with heavily distorted engine inlet flow. The HISTEC system has application to future engine designs by permitting a reduction in the built-in stall margin of 
the engine, allowing improvement to engine performance and a reduction in engine weight."

Following the HISTEC effort, the ACTIVE aircraft completed the Extended Range Demonstration (ERD) program, a joint effort with the USAF. The vectoring nozzles were used in various configurations at highspeed, low-altitude test conditions to investigate the aircraft performance improvements made possible by using thrust vectoring to offload the horizontal stabilizers, thereby decreasing drag and improving range. Preliminary results have been encouraging. An adaptive aircraft performance technology algorithm was also used to automatically find the optimal combination of control surface and nozzle positions to minimize drag.

Figure 11 shows a time history of a sinusoidal and step thrust-vector test sequence flown during this flight series. The measured vector forces from the thrustmount strain gages agree very well with the nozzle performance model in the nozzle controller. The excellent quality, strain-gage axial force data also agree well with in-flight thrust calculated using the gas generator method.

Following the recent refinement of the ACTIVE nozzle controller vector force-limiting logic and improvements to the hardware, the vectoring system envelope has been expanded to demonstrate higher vector forces and rates than previously achieved. The internal and external nozzle pressure profiles are being measured to improve the understanding of vectoring flow characteristics and to refine CFD development tools. ${ }^{34}$ The F-15 research activities have resulted in 185 reports and papers and 3 symposia.

\section{Laser Mass Flow Sensor}

Measurement of inlet and engine mass flow is important in system control and in determining thrust. A flight demonstration of a nonintrusive mass flow sensor, built by Physical Sciences, Inc. (PSI) (Andover, Massachusetts), is planned for the inlet of an F/A-18 airplane. Two very successful ground test demonstrations of the mass flux sensor in 1995 and 1996 were funded through the Small Business Innovative Research (SBIR) program and proved that a simple, lowpower, safe, laser-based sensor could provide very accurate measurements of full-scale engine inlet mass flux, even in the presence of high flow distortion. Miniaturization and hardening required to move the

\footnotetext{
\#The earlier HIDEC and PSC algorithms used stored values of distortion as a function of flight variables, and hence needed prior flight or wind-tunnel data.
}

sensor on to NASA Dryden's F/A-18 Systems Research Aircraft (SRA) will be followed by a future flight test program planned to demonstrate the operability and accuracy of the sensor in the harsh flight environment. Future studies may investigate the safety and performance benefits of integrating this high response sensor into an engine control system. ${ }^{35}$

\section{Hypersonics and Space Propulsion in the 1990's}

The 1990's brought a subtle shift back to propulsion research for hypersonics and space flight. In the early 1990's, NASA Dryden supported a direct-connect scramjet test at NASA Ames in the arc-heated facility. The scramjet combustor section had a high supersonic Mach number, and hydrogen burning was successfully accomplished.

In support of the National Aerospace Plane (NASP) program, an external burning experiment was proposed. The concept of external burning was to inject hydrogen into the vehicle base region at transonic speeds to reduce base drag. An initial test sponsored by the United States Navy tested a small panel on the wingtip of an F/A-18 airplane. Engineers at NASA Dryden assisted in this test. A follow-on, larger-scale test fixture was designed to be flown on the SR-71 airplane. Engineers at NASA Dryden computed the flow field in the test region on top of the fuselage and designed the test fixture, an instrumentation system, and the layout. The externalburning SR-71 experiment was cancelled before fabrication, but provided experience for future experiments.

\section{The Linear Aerospike SR-71 Experiment}

The X-33 aircraft is a concept demonstrator for a single-stage-to-orbit launch vehicle. The concept is powered by a linear aerospike rocket. An experiment was proposed to test a one-half-span, one-tenth-scale version of the X-33 aircraft. The LASRE was mounted on the upper aft end of the NASA SR-71 high-speed research airplane. A 40-ft long structure called a canoe, containing gaseous hydrogen tanks, helium tanks, controllers, and a water tank for engine cooling (fig. 12), formed a mount for a reflection plane. The "model," mounted above the reflection plane, contained the eight-chamber engine, a liquid oxygen tank, ignition fluid cartridges, and helium tanks. Forces, moments, pressures, and temperatures were measured on the experiment to evaluate engine operability and determine installed performance. 

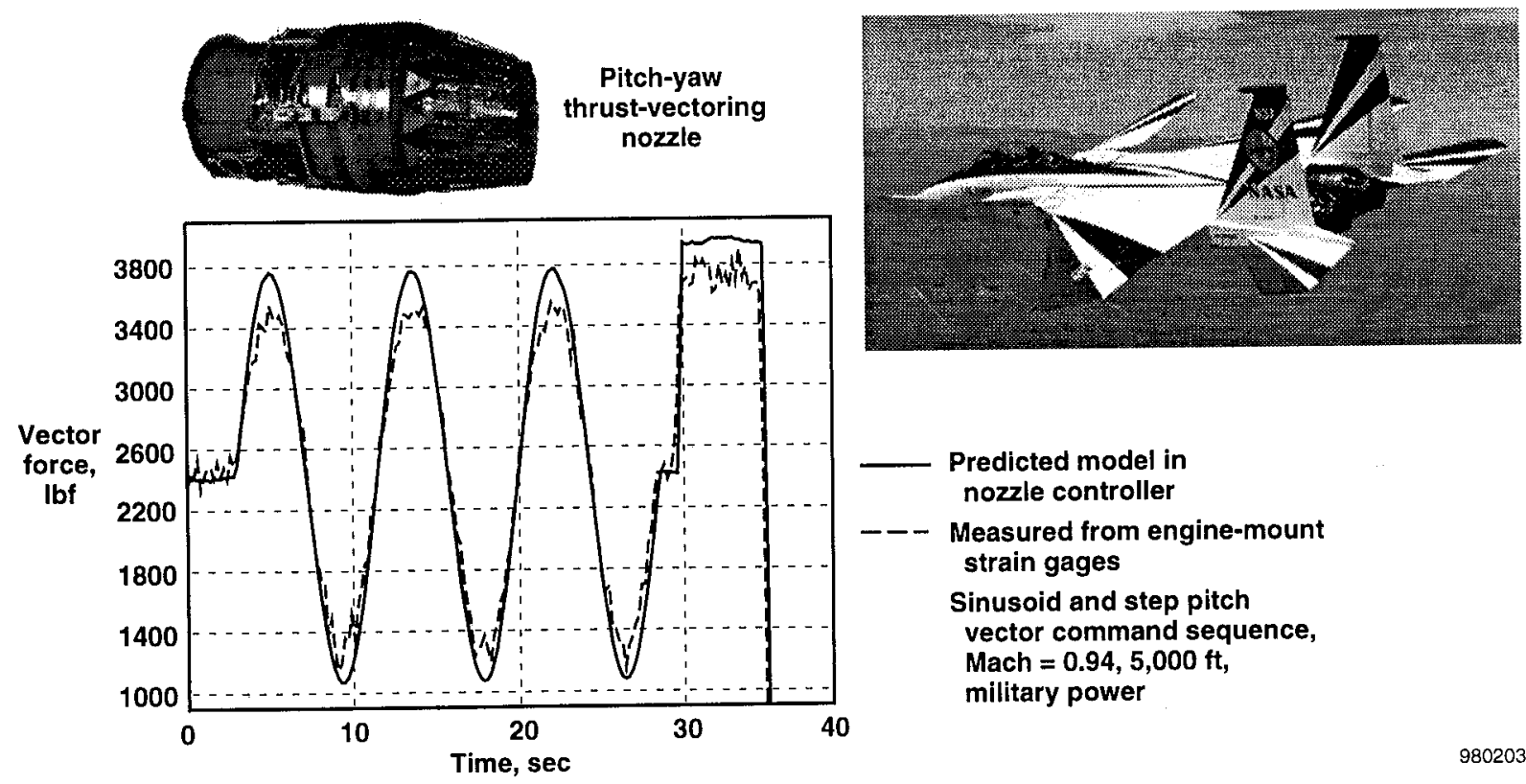

980203

Figure 11. F-15 ACTIVE thrust-vectoring nozzle results from extended range demonstration flights.

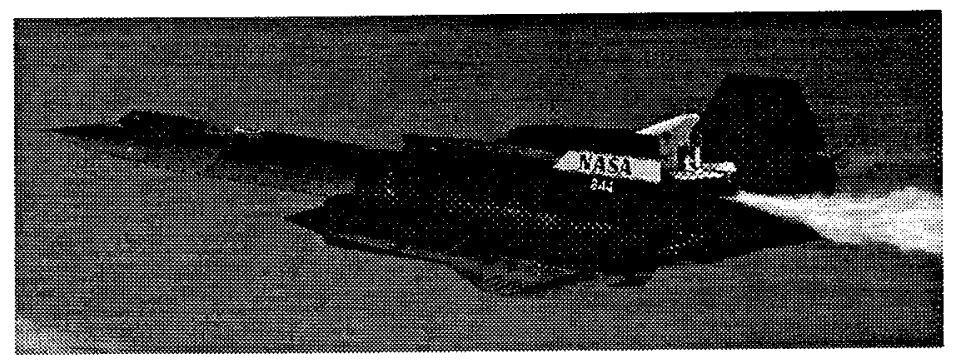

$\mathrm{GH}_{2}$ - Gaseous hydrogen

$\mathrm{He}$ - Gaseous helium

$\mathrm{H}_{2} \mathrm{O}$ - Water

$\mathrm{LN}_{2}$ - Liquid nitrogen

$\mathrm{LO}_{2}$ - Liquid oxygen

TEA/TEB Tetra-ethyl aluminum/ tetra-ethyl borane

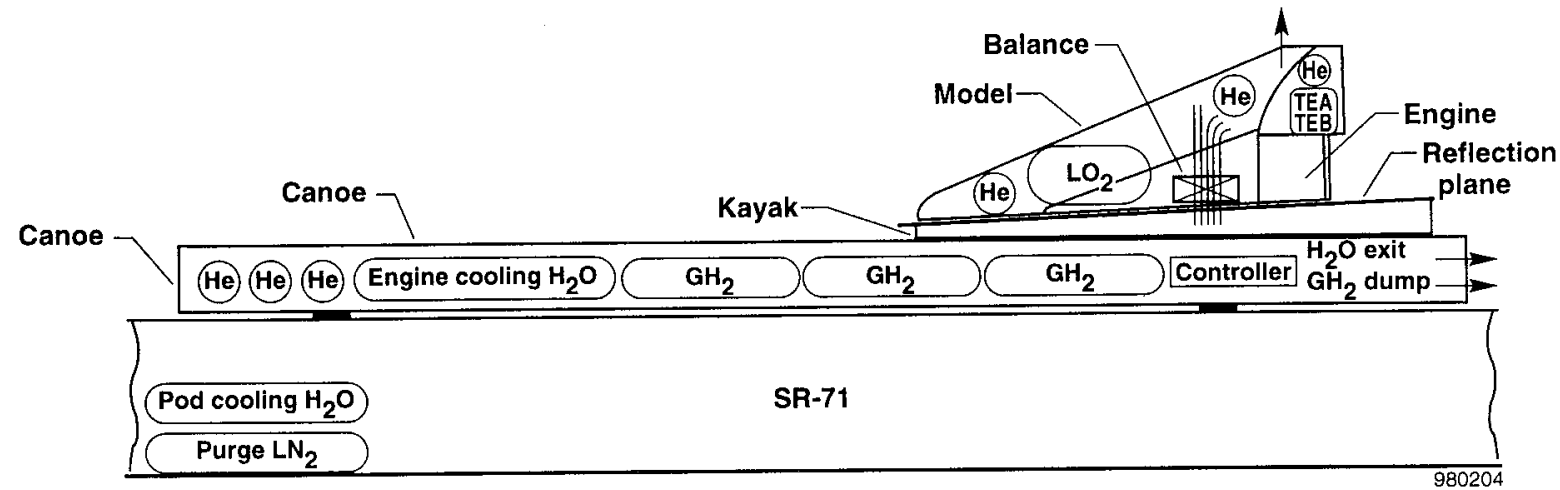

Figure 12. LASRE experiment pod on the SR-71 airplane. ${ }^{36}$

Because the linear aerospike engine uses the slipstream to help form the boundary of the expansion nozzle, flight data are critical to the demonstration of this concept and validation of CFD-based design methodology. Ground tests were conducted at the Air Force Research Laboratory (formerly USAF Phillips
Laboratory) (Edwards, California). Flights with inert gases were flown in late $1997 .{ }^{36}$ NASA Dryden also supported the ground-test and flight-test planning for the X-33 aircraft. The YF-12 and SR-71 research projects at NASA Dryden have resulted in 135 reports and papers. In addition, three symposia have been held. 


\section{The Hyper-X Vehicle}

Scramjet engines offer the potential of major improvements in propulsive efficiency at high speeds; however, their ability to produce positive net thrust is unproven and a lack of actual flight test data has significantly slowed scramjet technology application. The HRE has never been flight-tested. Manned flighttest programs have been proposed but have been too expensive or risky. An unmanned flight test is proposed using the Hyper-X vehicle. The project will test scramjet operation at Mach 7 and Mach 10. A 12-ft long, 5-ft span autonomous vehicle weighing $3000 \mathrm{lbm}$ will be dropped from a B-52 airplane, and boosted to the desired test conditions using a modified Pegasus ${ }^{\circledR}$. (Orbital Sciences Corporation, Fairfax, Virginia) booster. The scramjet will burn hydrogen for approximately $5 \mathrm{sec}$. NASA Dryden is responsible for simulation, design validation, flight operations, and flight research. Three flights are planned beginning in 2000.

\section{Acoustic Tests in the 1990's}

Acoustic tests in support of a high-speed civil transport have been conducted in the 1990's. First, the F/A-18 and F-16XL aircraft were flown over a microphone array to measure the acoustic characteristics of high nozzle pressure ratio jets over a range of speeds. NASA Langley made the acoustics measurements, and NASA Dryden operated the airplanes, provided space position and onboard data, and calculated engine parameters of interest. A static test was also performed by NASA Dryden. These data were used to update and correct the noise prediction methods used. A large error in the methods used in predicting noise for high-altitude flyovers was found as a result of these tests.

A similar test was later conducted on the F-15 ACTIVE airplane using the vectoring nozzles to vary nozzle expansion ratio independently of nozzle pressure ratio and forward velocity. Tests were also flown with the exhaust jets vectored toward and away from each other. The NASA Dryden simulation was used to develop flight techniques that allowed power and Mach number to be held closely during flyovers by adjusting the flightpath angle.

\section{Technology Transition and Lessons Learned}

Considerable technical knowledge in propulsion research has been gained over the past 30 years. In many cases, flight research and demonstration of nearoperational hardware has accelerated the transition of these technologies into use on operational airplanes Many lessons have been learned that are valuable and should not be lost for future investigations. Transition of recent significant NASA propulsion control, propulsion, and flight control integration technology has previously been discussed. ${ }^{17}$ The following list includes some of the most important lessons learned and examples of technology transition.

- Fly early: New propulsion concepts benefit from an early flight evaluation. Fly as soon as a safe test article is available, and find the problems early when the fixes are not so expensive and schedule impacts are less.

- Instrument: Develop and install enough instrumentation to find the unexpected, which may require the development of sensors, data acquisition systems, and data processing and analysis methods before advanced propulsion concepts can be evaluated. Examples of instrumentation development include the following:

- F-11I transducers-Miniature transducers were developed that could be close-coupled for making high-frequency response pressure measurements. Initial transducers were very temperaturesensitive, requiring development of in-flight nulling rakes and later, making simultaneous steady-state and dynamic pressure measurements.

- YF-12 instrumentation-High-temperature instrumentation was required to operate at temperatures as high as $800{ }^{\circ} \mathrm{F}$ in the inlet and $1000^{\circ} \mathrm{F}$ in the engine area. Extensive developments were needed; eddy-current displacement transducers were finally able to perform accurately in this environment.

- F/A-18 rakes-Original rakes had to built into the airplane structure during airplane construction. Rakes that cost 80 percent less and had a negligible installation time were developed and tested successfully.

- Test over a large envelope: Fly enough tests to find the unexpected. The F100 DEEC tested into parts of the flight envelope where many problems were expected, but few occurred. The F100 EMD compressor stall problem occurs in the extreme corner of the envelope only on snaps to idle. The F100 EMD throttle response problem was discovered in close formation flying. The SR-71 propulsion-related rolling and yawing moments were found to be more powerful than the flight control system at high speed. Mechanical and performance discrepancies for vectoring nozzles were found only at the highest Mach numbers and 
highest power settings. The MD-11 PCA system, designed for low speed and low altitudes, also worked well at high altitude, at high speed, and with an aft center of gravity.

- Use digital control when possible: Digital control systems offer tremendous capability and flexibility. Use the class " $B$ " single-channel, fail-safe software if applicable, because the software is quick, flexible, and cost-effective. Maximize the use of class " $\mathrm{B}$ " software to add trims to class "A" software commands, as opposed to making extensive changes to class " $\mathrm{A}$ " software only to meet the same objectives. The digital data buses used on the HARV, ACTIVE, and MD-11 aircraft can make huge numbers of parameters available (4000 on the MD-11 airplane), but beware of time delays and unpredictable latencies when using this data for dynamic analysis!

- Build in flexibility: Build maximum flexibility into propulsion experiments hardware. Design systems to provide room for more instrumentation, better data processing, and analysis software. Build in all practical flexibility; let the flying airplane be the closed-loop control research facility.

- Expect differences: Programs that did better than predicted in flight include the F100 DEEC, which had better than expected performance, reliability, and maintainability; the HIDEC/ADECS, which did better than expected and had 5-10 percent performance improvements achieved by making only software changes; and the YF- 12 inlet-radiated noise attenuation that had lower-than-expected inlet throat Mach numbers. Also, the YF-12 cooperative control worked better than expected and had a 7-percent range improvement; the F-111E IPCS showed the value of digital control and control integration was higher than expected; and the MD-11 PCA did better than expected. All software hands-off landings were made with no flight control surfaces used and no pilot training needed. The F/A-18 inlet rake was simpler and worked better than initially expected, and inlet distortion during dynamic maneuvers in the F/A-18 airplane was somewhat lower than at the same conditions in steady state.

Programs that did worse than predicted in flight include the AMK, which performed much worse than predicted when exposed to real-world ignition sources in the CID; and the F-15 airplane, whose throttles-only control was much worse than expected based on ground simulations and whose second- and third-order effects were not properly modeled. Also, the X-15 ramjet showed that severe heating can result from shock-shock and shockboundary layer interactions. Unexpected compressor stalls were found to occur in the extreme upper left corner of the F-15 flight envelope. The F-15 nozzle vector effectiveness was much less than predicted from CFD or wind-tunnel tests at points in the flight envelope. No way existed to predict the decreased effectiveness with CFD or ground test. Also, the XB-70 base drag was higher than expected and had a big effect on range.

- Develop simulations: Simulation can provide a window into the operation of a new propulsion concept. Simulation work is often assumed to belong somewhere else, but NASA Dryden simulations made it possible to develop and evaluate concepts such as HIDEC and PCA; to improve data quality and flight safety on the HARV, ACTIVE, and LASRE; and fix problems on the DEEC.

- Report results: A total of 490 reports and papers have resulted from NASA Dryden propulsion research. Nine symposia have also been held, resulting in effective technology transfer.

- Flight will speed technology transition: The YF-12 research began in the early 1970's and flew in the late 1970's, and the concepts were implemented on the SR-71 airplane in 1983. The DEEC research began in the mid-1970's, was flown in the early 1980 's, and went into production for the F100-PW-220 engine in 1986. The HIDEC began with studies in the early $1980^{\prime}$ 's, flew in the mid-1980's, and is now being applied to the F100-PW-229 and advanced engines. Performanceseeking control flew in the early 1990's, and parts are now in the engines of the F-22 airplane.

\section{CONCLUDING REMARKS}

Propulsion flight research from 1967 to 1997 has had many important results. Propulsion, propulsion/flight control, and digital control research have been shown to have significant performance benefits for high performance and supersonic cruise airplanes, and many lessons have been learned. The YF-12 cooperativecontrol flight research concept was implemented on the SR-71 fleet. Flight research on the digital electronic engine control system on the NASA F-15 airplane led to production use in the F-15 and F-16 aircraft. More recent highly integrated digital electronic control and performance-seeking control flight research is now being applied to advanced engines. Emergency flight 
control using only computer-controlled thrust has been validated for fighter and transport airplanes. Flight tests of thrust-vectoring nozzles and linear aerospike engines is continuing. The flight evaluation and demonstration of these technologies have played a significant role in transitioning the concepts to production and operational use on a timely basis.

\section{REFERENCES}

${ }^{1}$ Burcham, Frank W., Jr. and Ronald J. Ray, The Value of Early Flight Evaluation of Propulsion Concepts Using the NASA F-15 Research Airplane, NASA TM-100408, 1987.

${ }^{2}$ Burcham, Frank W., Jr. and Donald R. Bellman, "A Flight Investigation of Steady-State and Dynamic Pressure Phenomena in the Air Inlets of Supersonic Aircraft," Inlets and Nozzles for Aerospace Engines, AGARD-CP-91-71, Dec. 1971.

${ }^{3}$ Burcham, Frank W., Jr. and Jack Nugent, Local Flow Field Around a Pylon-Mounted Dummy Ramjet Engine on the X-15-2 Airplane for Mach Numbers From 2.0 to 6.7, NASA TN-D-5638, 1970.

${ }^{4}$ Burcham, Frank W., Jr. and Peter G. Batterton, "Flight Experience With a Digital Integrated Propulsion Control System on an F-111E Airplane," AIAA-76-653, July 1976.

${ }^{5}$ Anderson, D. L., G. F. Connolly, F. M. Mauro, and P. J. Reukauf, $Y F-12$ Cooperative Airframe/Propulsion Control System Program: Volume I, NASA CR-163099, 1980.

${ }^{6}$ Burcham, Frank W., Jr., "Summary of HIDEC Results," Highly Integrated Digital Electronic Control Symposium, NASA CP-3024, 1987, pp. 358-364.

${ }^{7}$ NASA Dryden Flight Research Center, $Y F-12$ Experiments Symposium: Volume 3, NASA CP-2054, 1978.

${ }^{8}$ Burcham, Frank W., Jr., Gary A. Trippensee, David F. Fisher, and Terrill W. Putnam, "Summary of Results of NASA F-15 Flight Research Program," AIAA-86-9761, Apr. 1986.

${ }^{9}$ Johnson, Steven A., Aircraft Ground Test and Subscale Model Results of Axial Thrust Loss Caused by Thrust Vectoring Using Turning Vanes, NASA TM-4341, 1992.
${ }^{10}$ Burcham, Frank W., Jr., An Investigation of Two Variations of the Gas Generator Method to Calculate the Thrust of the Afterburning Turbofan Engines Installed in an F-111A Airplane, NASA TN-D-6297, 1971.

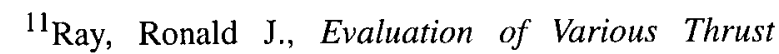
Calculation Techniques on an F404 Engine, NASA TP-3001, 1990.

${ }^{12}$ Conners, Timothy R., Measurement Effects on the Calculation of In-Flight Thrust for an F404 Turbofan Engine, NASA TM-4140, 1989.

${ }^{13}$ Fiorentino, A., Antimisting Kerosene JT3 Fuel System Integration Study, NASA CR-4033, 1987.

${ }^{14}$ Burcham, Frank W., Jr., John J. Burken, Trindel A. Maine, and C. Gordon Fullerton, Development and Flight Test of an Emergency Flight Control System Using Only Engine Thrust on an MD-11 Transport Airplane, NASA TP-97-206217, 1997.

${ }^{15}$ Arnaiz, Henry H., John B. Peterson, Jr., and James C. Daugherty, Wind-Tunnel/Flight Correlation Study of Aerodynamic Characteristics of a Large Flexible Supersonic Cruise Airplane (XB-70-1): III-A Comparison Between Characteristics Predicted From Wind-Tunnel Measurements and Those Measured In Flight, NASA TP-1516, 1980.

${ }^{16}$ Burcham, Frank W., Jr., Donald L. Hughes, and Jon K. Holzman, Steady-State and Dynamic Pressure Phenomena in the Propulsion System of an F-111A Airplane, NASA TN-D-7328, 1973.

${ }^{17}$ Burcham, Frank W., Jr., Glenn B. Gilyard, and Lawrence P. Myers, Propulsion System/Flight Control Integration and Optimization: Flight Evaluation and Technology Transition, NASA TM-4207, 1990.

\footnotetext{
${ }^{18}$ Schweikhard, William G. and Earl J. Montoya, "Research Instrumentation Requirements for Flight/Wind-Tunnel Tests of the YF-12 Propulsion System and Related Flight Experience," Instrumentation for Airbreathing Propulsion, The Massachusetts Institute of Technology, 1974, pp. 19-39.

${ }^{19}$ Smith, R. H. and F. W. Burcham, Jr., "Instrumentation for In-Flight Determination of SteadyState and Dynamic Inlet Performance in Supersonic Aircraft," Instrumentation for Airbreathing Propulsion, The Massachusetts Institute of Technology, 1974, pp. 41-58.
} 
${ }^{20}$ Lasagna, Paul L., Karen G. Mackall, Frank W. Burcham, Jr., and Terrill W. Putnam, Landing Approach Airframe Noise Measurements and Analysis, NASA TP-1602, 1980.

${ }^{21}$ Burcham, Frank W., Jr., Terrill W. Putnam, Paul L. Lasagna, and $O$. Owen Parish, Measured Noise Reductions Resulting From Modified Approach Procedures For Business Jet Aircraft, NASA TM-X-56037, 1975.

${ }^{22}$ Burcham, Frank W., Jr., Paul L. Lasagna, and Stanley C. Oas, Measurements and Predictions of Flyover and Static Noise of a TF30 Afterburning Turbofan Engine, NASA TP-1372, 1978.

${ }^{23}$ Burcham, Frank W., Jr., Timothy R. Conners, and Michael D. Maxwell, "Flight Research Using F100 Engine P680063 in the NASA F-15 Airplane," ASME-95-GT-119, June 1995.

${ }^{24}$ Burcham, F. W., L. P. Myers, J. Nugent, P. Lasagna, and L. D. Webb, "Recent Propulsion System Flight Tests at NASA Dryden Flight Research Center," AIAA-81-2438, Nov. 1981.

${ }^{25}$ Burcham, F. W., Jr., L. P. Myers, and K. R. Walsh, "Flight Evaluation of a Digital Electronic Engine Control in an F-15 Airplane," Journal of Aircraft, vol. 22, no. 12, Dec. 1985, pp. 1072-1078.

${ }^{26}$ Orme, John S. and Gerard S. Schkolnik, Flight Assessment of the Onboard Propulsion System Model for the Performance Seeking Control Algorithm on an F-15 Aircraft, NASA TM-4705, 1995.

${ }^{27}$ Powers, Sheryll Goecke, Editor, An Electronic Workshop on the Performance Seeking Control and Propulsion Controlled Aircraft Results of the F-15 Highly Integrated Digital Electronic Control Flight Research Program, NASA TM-104278, 1995.

${ }^{28}$ Walsh, Kevin R., Summary of the Effects of Engine Throttle Response on Airplane Formation-Flying Qualities, NASA TM-4465, 1993.
${ }^{29}$ Alexander, R. I., and R. J. Ray, Development and Flight Test of a Real-Time Thrust Measurement Technique on the X-29A/F404 Advanced Technology: Demonstrator, NASA TM-101707, 1989.

${ }^{30}$ Yechout, T. R. and K. B. Braman, Development and Evaluation of a Performance Modeling Flight Test Approach Based on Quasi-Steady-State Maneuvers, NASA CR-170414, 1984.

${ }^{31}$ Walsh, Kevin R., Andrew J. Yuhas, John G. Williams, and William G. Steenken, Inlet Distortion for an F/A-18A Aircraft During Steady Aerodynamic Conditions up to $60^{\circ}$ Angle of Attack, NASA TM-104329, 1997.

${ }^{32}$ Burcham, Frank W., Jr., Trindel A. Maine, C. Gordon Fullerton, and Lannie Dean Webb, Development and Flight Evaluation of an Emergency Digital Flight Control System Using Only Engine Thrust on an F-15 Airplane, NASA TP-3627, 1996.

${ }^{33}$ Conners, Timothy R., "Predicted Performance of a Thrust-Enhanced SR-71 Aircraft With an External Payload," ASME-95-GT-116, June 1995.

${ }^{34}$ Smolka, James W., Laurence A. Walker, Gregory H. Johnson, Gerard S. Schkolnik, Curtis W. Berger, Timothy R. Conners, John S. Orme, Karla S. Shy, and C. Bruce Wood, "F-15 ACTIVE Flight Research Program," SETP Fortieth Symposium Proceedings, Sept. 1996, pp. 112-145.

${ }^{35}$ Miller, Michael F., William J. Kessler, and Mark G. Allen, "Diode Laser-Based Air Mass Flux Sensor for Subsonic Aeropropulsion Inlets," Applied Optics, vol. 35, no. 24, Aug. 1996, pp. 4905-4912.

${ }^{36}$ Corda, Stephen, et al, "Blackbird puts LASRE to the Test," Aerospace America, Feb. 1998, pp. 25-29. 
Public reporting burden for this collection of information is estimated to average 1 hour per response, including the time for reviewing instructions, searching existing data sources, gathering and maintaining the data needed, and completing and reviewing the collection of information. Send comments regarding this burden estimate or any other aspect of this collection of information, intuding VA 22202-4302, and to the Office of Management and Budget, Paperwork Reduction Project (0704-018B), Washington, DC 20503.

\begin{tabular}{|l|l|l|}
\hline 1. AGENCY USE ONLY (Leave blank) & $\begin{array}{c}\text { 2. REPORT DATE } \\
\text { July } 1998\end{array}$ & $\begin{array}{c}\text { 3. REPORT TYPE AND DAT } \\
\text { Technical Paper }\end{array}$ \\
\hline
\end{tabular}

4. TITLE AND SUBTITLE

Propulsion Flight Research at NASA Dryden From 1967 to 1997

6. AUTHOR(S)

Frank W. Burcham, Jr., Ronald J. Ray, Timothy R. Conners, and Kevin R. Walsh

7. PERFORMING ORGANIZATION NAME(S) AND ADDRESS(ES)

NASA Dryden Flight Research Center

P.O. Box 273

Edwards, California 93523-0273

WU 523-90-24-00-RP-00-000

9. SPONSORING/MONITORING AGENCY NAME(S) AND ADDRESS(ES)

10. SPONSORING/MONITORING AGENCY REPORT NUMBER

National Aeronautics and Space Administration

Washington, DC 20546-0001

NASA/TP-1998-206554

11. SUPPLEMENTARY NOTES

Presented at the AIAA/SAE/ASME/34th Joint Propulsion Conference, Cleveland, Ohio, July 13-15, 1998, AIAA 98-3712.

12a. DISTRIBUTION/AVAILABILITY STATEMENT

12b. DISTRIBUTION CODE

Unclassified-Unlimited

Subject Category 07

13. ABSTRACT (Maximum 200 words)

From 1967 to 1997, pioneering propulsion flight research activities have been conceived and conducted at the NASA Dryden Flight Research Center. Many of these programs have been flown jointly with the United States Department of Defense, industry, or the Federal Aviation Administration. Propulsion research has been conducted on the XB-70, F-111A, F-111E, YF-12, JetStar, B-720, MD-11, F-15, F-104, Highly Maneuverable Aircraft Technology, F-14, F/A-18, SR-71, and the hypersonic X-15 airplanes. Research studies have included inlet dynamics and control, in-flight thrust computation, integrated propulsion controls, inlet and boattail drag, wind tunnel-to-flight comparisons, digital engine controls, advanced engine control optimization algorithms, acoustics, antimisting kerosene, in-flight lift and drag, throttle response criteria, and thrust-vectoring vanes. A computer-controlled thrust system has been developed to land the F-15 and MD-11 airplanes without using any of the normal flight controls. An F-15 airplane has flown tests of axisymmetric thrust-vectoring nozzles. A linear aerospike rocket experiment has been developed and tested on the SR-71 airplane. This paper discusses some of the more unique flight programs, the results, lessons learned, and their impact on current technology.

\begin{tabular}{|c|c|c|c|}
\hline \multirow{2}{*}{\multicolumn{3}{|c|}{$\begin{array}{l}\text { 14. SUBJECT TERMS } \\
\text { Engine, Flight test, Inlet, Nozzle, Propulsion }\end{array}$}} & $\begin{array}{l}\text { 15. NUMBER OF PAGES } \\
29\end{array}$ \\
\hline & & & $\begin{array}{l}\text { 16. PRICE CODE } \\
\text { A03 }\end{array}$ \\
\hline $\begin{array}{l}\text { 17. SECURITY CLASSIFICATION } \\
\text { OF REPORT }\end{array}$ & $\begin{array}{l}\text { 18. SECURITY CLASSIFICATION } \\
\text { OF THIS PAGE }\end{array}$ & $\begin{array}{l}\text { 19. SECURITY CLASSIFICATION } \\
\text { OF ABSTRACT }\end{array}$ & 20. LIMITATION OF ABSTRACT \\
\hline Unclassified & Unclassified & Unclassified & Unlimited \\
\hline
\end{tabular}

